\title{
LA FAMILIA DE DON LEONARDO SOLER DE CORNELLA. UN LINAJE DE CABALLEROS EN ELCHE DURANTE EL SIGLO XVIII
}

\author{
Ramón BALDEQUÍ ESCANDELL \\ Jesús PRADELLS NADAL \\ Universidad de Alicante.
}

\section{Introducción.}

D. Leonardo Soler de Cornellá fue un eclesiástico cuya carrera responde al arquetipo del clérigo con inquietudes de su época. Nacido en Elche el 10 de abril de 1736, en el seno de una familia de la pequeña nobleza local, y muerto en Orihuela en 1796, el día 27 del mismo mes, su vida, por lo que sabemos, transcurrió en su mayor parte entre ambas ciudades y la comarca que las une. Hombre cultivado, atraído por los temas de la predicación, a cuyo ministerio estaba volcado, Soler es un buen exponente de la generación que entre 1760 y 1770 intentó tímidamente introducir en Orihuela las ideas ilustradas. Catedrático de Sagrada Escritura, y regente de estudios del Seminario orcelitano, párroco sucesivamente de Almoradí y de la iglesia de San Juan Bautista del Arrabal de Elche y canónigo magistral en la catedral oriolana desde 1777, sus inquietudes intelectuales le llevaron entre 1775 y 1776, a realizar excavaciones en el yacimiento de La Alcudia, próximo a su villa natal, las cuales adquirieron cierta resonancia y dieron lugar a que se enzarzara en una agria polémica con el conde de Lumiares, que impulsó a éste a escribir su Carta al Sr. D. Juan Antonio Mayans y Siscar...dándole noticia de los descubrimientos hechos en la Alcudia inmediata a la Villa de Elche.

Aparte algunos sermones, la única obra que D. Leonardo Soler dio a las prensas fue el Aparato de eloqüencia para los sagrados oradores (Valencia, Benito Monfort, 1788 y 1790, en 6 volúmenes in-quarto), destinada a formar a los predicadores sobre el modelo de Cicerón, obra que ya analizamos en un trabajo anterior (1) y en la que se muestra buen conocedor de los autores cläsicos, Padres de la Iglesia y humanistas de los siglos XVI al XVIII (Hugo Grocio, Vives, Fr. Luis de Granada, Pedro Juan Perpiñá, Lampillas, los PP. Mohedano, entre otros), debelador del deísmo y partidario de un 
concepto de la oratoria sagrada más basado en los aspectos artísticos y técnicos del sermón que en una renovación de la figura espiritual del orador. La obra y el autor merecieron el elogio del riguroso D. Joaquín Lorenzo Villanueva, quien en 1825, exilado en Londres, evocó en su Vida literaria la amistad de que en su juventud le hizo objeto don Leonardo. (2)

El propósito del presente trabajo es mostrar el entorno familiar en el que se desenvolvió la vida del autor, con el fin de dar una idea del medio social del que procedía y del modo como encaja en el mismo este representante menor de la "ilustración" de la segunda mitad del siglo XVIII. Pretendemos con ello mostrar el caldo de cultivo que hizo posible la aparición de nuestra figura, como representante arquetípico de esa "intelectualidad" provinciana que entrevemos en los relatos de viajeros tales como Cavanilles o Jovellanos, al tiempo que, junto con el trabajo anterior y otro que tenemos en curso de elaboración, buscamos completar, desde diferentes puntos de vista, nuestra imagen de la figura de don Leonardo Soler de Cornellá.

\section{Los orígenes del linaje.}

El primer antepasado de que tenemos conocimiento es Pedro Soler quien, procedente de Barcelona, ya estaba instalado en Elche en 1483. Casado con Catalina Portes, viuda de Jaime Crespo, aparece titulado como "labrador". De su hijo Juan Soler y Portes, armado caballero en Monzón por Felipe II y acreditado por privilegio de 22 de octubre de 1552, arranca la prosapia nobiliaria de la familia y el apellido compuesto, al contraer matrimonio en segundas nupcias con Violante Cornellá, en fecha desconocida. (3)

De los 5 hijos varones de este Juan Soler, uno de ellos, Gaspar Soler y Cornellá, quien en 1564 era calificado de "donzell", dio origen a una rama del linaje, extinguida a mediados del siglo XVII después de haber alcanzado honores y fortuna. (4) De Juan Soler y Cornellá, otro de los hijos, partieron las otras dos líneas con que llegó a contar la familia: de ellas una, la de los descendientes de Juan Soler y Daroca, se extinguió en la vorágine de la guerra de Sucesión (5), mientras que la otra, procedente de su hermano Pedro Soler, logró remontar la crisis y llegar hasta el siglo XX.

A partir de la fecha de su ennoblecimiento, el linaje de los Soler de Cornellá entrará en la dinámica propia de la pequeña nobleza ilicitana. El propio Juan Soler adquirió derecho de sepultura en la iglesia parroquial de Santa María (6), y sus descendientes enlazarán en matrimonio con representantes de las familias aristocráticas de la ciudad, como los Malla, los Ortiz o los Caro. (7) Su hijo Gaspar Soler y Cornellá fue familiar del Santo Oficio (8), mientras que su nieto Pedro Soler y Daroca, el 7 de diciembre de 1577, obtuvo sentencia favorable del Consejo de Aragón en pleito con los señores de Elche, declarando que éstos no podían tener jurisdicción sobre los caballeros. (9) Un don Andrés Soler y Grañana, sobrino de éste, fue comendador de la orden de Montesa. (10)

Pero ciñéndonos a la línea de la descendencia de don Pedro Soler de Cornellá y 
Daroca, que va a acaparar nuestra atención, diremos que su hijo, don Leonardo Soler de Cornellá y Malla, acudió a cortes en Monzón en 1626 y, según indican las fuentes, "se hizo noble en el año 1653" (11); mientras que su nieto, don Pedro Soler de Cornellá y Caro, familiar del Santo Oficio, asistió a las cortes celebradas en Valencia en 1645. (12) Fue hijo de éste don Pedro Soler de Cornellá y Malla, casado en segundas nupcias con doña María Llanos, que fue caballero de Montesa, capitán de la compañía de caballos de Elche, que murió en 23 de junio de 1701 (13), y cuyos hermanos don Antonio y doña María sufrieron duramente, como veremos, las consecuencias de la derrota en la guerra de Sucesión. Con su hijo, don Leonardo Soler de Cornellá y Vaillo de Llanos, comienza la fase de la historia familiar que constituye el objeto del presente trabajo.

\section{Los Soler de Cornellá en el siglo XVIII.}

Al comenzar el siglo décimoctavo, encontramos al frente de la familia en Elche a D. Leonardo Soler de Cornellá y Vaillo de Llanos, nacido en dicha villa el día 28 de junio de 1684 y casado en Onteniente, en diciembre de 1724, con doña Vicenta Ros de Ursinos y Barberá. (14) Don Leonardo tuvo un hermanastro, Don Tomás Soler de Cornellá y Anglesola, fruto del primer matrimonio de su padre con doña María Anglesola, natural de la ciudad de Valencia, el cual heredaría uno de los vínculos fundados por su bisabuelo, el noble valenciano D. Guillem Ramón Anglesola. (15) También tuvo don Leonardo dos hermanos enteros, doña Manuela y D. Pedro Soler: éste, entregado a la carrera eclesiástica, fue beneficiado en Santa María de Elche, y habiendo heredado a su tío D. Antonio, muerto en la prisión de Murcia, gozó de una considerable fortuna, muy por encima de las normales entre los eclesiásticos ilicitanos de su tiempo. (16)

Así pues, en la época de nuestro canónigo, la suya era la única rama de Soler de Cornellá existente en Elche, ya que los indicios apuntan a que el hermanastro de su padre, D. Tomás Soler de Cornellá y Anglesola, residía en Valencia, de donde procedían su familia materna y la de su esposa, mientras que la otra rama familiar existente en tiempos aún próximos, se había extinguido con la guerra civil que inició el siglo. (17)

Como es natural, los Soler de Cornellá siguieron manteniendo en el nuevo siglo la costumbre de contraer matrimonio con miembros de la nobleza, pero si durante el dieciséis y el diecisiete los enlaces se limitaron al ámbito de la ilicitana o como mucho, de la comarcana, al llegar el XVIII los casamientos convenientes se buscarán más allá del reducido círculo local. Ya a fines del seiscientos dio la señal D. Pedro Soler, contrayendo su primer matrimonio con una dama valenciana; ahora será este comportamiento el patrón general, a partir de la boda de D. Leonardo Soler con doña Vicenta Ros, nacida en Valencia, aunque de familia procedente de Onteniente. (18) Y este mismo don Leonardo Soler y Llanos labrará nueva sepultura para los Soleres en la iglesia de Santa María, reconstruida entre fines del siglo XVII y principios del XVIII tras la ruina de la construcción renacentista anterior.(19) Esta nueva sepultura estaba situada "junto a la pila y pilar del crusero de la parte de medio día" (20) de dicha iglesia, en cuyo 
término parroquial y muy cerca de la misma, en la "plasuela de Santa María", estaba la casa familiar. (21)

En ella pasó sus primeros años el futuro canónigo, quien quedó huérfano de madre antes de los cuatro, pues doña Vicenta Ros murió el 26 de marzo de 1740, quizá a consecuencia del parto de don Vicente Soler, acontecido un mes antes. (22) Según el orden sucesorio que don Leonardo Soler de Cornellá y doña Vicenta Ros establecieron para el vínculo que fundaron en su testamento pasado ante el notario de Elche Diego Mira el 25 de marzo de 1740, don Leonardo era el cuarto de cinco hermanos varones, a saber, don Francisco, don Dionisio y don Pedro, mayores que él, por este orden, y don Vicente, menor. También había una hermana, doña Josefa, que por su condición femenina era la última llamada a suceder en dicho vínculo, aunque es posible que fuera la mayor en edad, atendiendo a que en 1746 casó con Francisco Martínez de la Raga, natural de Valencia. (23)

Prácticamente nada sabemos de D. Dionisio, que llevaba el nombre de su abuelo materno, y muy poco también de D. Pedro, quien casó en 1753 con Joaquina Llanzol, natural de Valencia, y que en 1765 participó junto con su hermano D. Leonardo en el desaire colectivo que la nobleza ilicitana propinó a la duquesa de Arcos a su paso por Murcia y Cartagena, causando a su hermano el duque un tremendo sofión. (24) D. Vicente profesó en 1753 en la orden de los Caballeros Hospitalarios de San Juan de Jerusalén, y en 1755 ingresó como caballero guardiamarina. (25) En mayo de 1784 tomó posesión de la encomienda del Temple de Huesca: en los documentos se titula comendador de Ambel, y aparece favoreciendo a sus sobrinas, hijas de D. Francisco, cediéndoles la pensión de que gozaba sobre el vínculo fundado por su tío el beneficiado $\mathrm{D}$. Pedro Soler y su parte en la herencia de su hermano D. Leonardo. (26)

Respecto de don Leonardo Soler de Cornellá, a quien con justicia podemos considerar el miembro más ilustre de la familia, nació, como vimos, el 10 de abril de 1736, y fue bautizado en la iglesia de Santa María, en Elche. Tras haber cursado los estudios de gramática y con diez años, aproximadamente, entró a estudiar filosofía en el colegio de la Compañía de Jesús en Orihuela, en donde permaneció durante dos cursos, para pasar luego al llamado Colegio de la Purísima Concepción, que era uno de los dos seminarios fundados en Orihuela por el obispo don Juan Elías Gómez de Terán. En él permaneció Soler durante siete años, estudiando teología escolástica y moral y Sagrada Escritura, al término de los cuales se recibió de Maestro en Artes por la universidad de Orihuela, y de doctor en Teología por la de Gandía, en 1755.

En posesión ya de un sólido bagaje cultural en el campo de las humanidades y en el de la teología y escolástica suarecianas, y ordenado de presbítero "a título de patrimonio y suficiencia", don Leonardo se entregó a la carrera de las oposiciones, y así optó al curato de San Juan de Alicante, al que fue consultado en primer lugar, aunque no parece que obtuviese la colación, y en 1758 , a la canongía magistral de la catedral de Almería, de cuya diócesis fue visitador general por el obispo don fray Gaspar de Molina y Rocha; y también fue examinador sinodal de la diócesis de Guadix en tiempo del obispo don Francisco Alejandro Bocanegra y Xibaja, quien creemos que ejerció 
cierta influencia sobre su pensamiento contrario al deísmo. Fue luego catedrático de Sagrada Escritura y regente de estudios del seminario de Orihuela, en que había cursado sus estudios, puestos que ocupaba en 1760, y después párroco de Almoradí al menos entre 1765 y 1773. Posteriormente lo fue de la iglesia de San Juan Bautista del Arrabal de Elche, de la que era patrono el duque de Arcos, marqués de Elche, pero que se proveía por riguroso concurso sinodal; parroquia que sirvió hasta que en 1777 obtuvo por oposición la canongía magistral de la catedral de Orihuela. (27) En el desempeño de dicha canongía fue examinador sinodal por el obispo don José Tormo y Juliá, y visitador general del obispado sede vacante. Y también, como tal canónigo, a quienes estaban vinculados ambos cargos, fue rector y juez general de la universidad de Orihuela desde el 29 de septiembre de 1786 hasta igual día de 1788. (28) Fue durante el desempeño de esta canongía cuando publicó su Aparato de eloqüencia en seis volúmenes, su obra principal, que salió bellamente impresa de la casa de don Benito Monfort, en Valencia, en 1788-1790, y cuando trabó amistad con don Joaquín Lorenzo Villanueva, quien, con 19 años, también había concurrido a la misma oposición a magistral que ganó Soler. Don Leonardo murió de sesenta años en Orihuela, el 27 de abril de 1796, muy poco después que su hermano mayor don Francisco, y sin haber tenido ocasión de redactar testamento. (29)

En cuanto al hermano mayor D. Francisco, nacido el 6 de octubre de 1726, casó en 1763 con doña María Rafaela Juan y Jiménez de Urrea, nacida en Alicante el 24 de julio de 1742, que por parte de su madre era nieta de los condes de Berbedel y cuyo padre, D. Nicolás Juan, era medio hermano del famoso matemático y marino D. Jorge Juan y de D. Bernardo Juan y Santacília, uno de los mayores terratenientes ilicitanos de la época y señor de Asprillas como heredero de los Santacília, que detentaban el señorío desde 1616. (30) Don Francisco Soler de Cornellá, que era abogado de los Reales Consejos y se titulaba "caballero maestrante de la Real Maestranza de la ciudad de Valencia" y "Familiar numerario y Alguacil mayor del Santo Oficio de la Imauisición de Murcia en esta villa de Elche", ocupó en diversas ocasiones el cargo de alcalde ordinario de la villa de Elche: sabemos que lo era en 1752, en ocasión de la visita que realizó el oidor Ascensio de Morales, registrando los archivos de la diócesis oriolana (31), y en 1765, cuando la nobleza local, al paso de la hermana del duque de Arcos, realizó una famosa excursión a tierras murcianas, que terminó de modo muy poco galante, con un desaire a la duquesa, como más adelante tendremos ocasión de ver. Tuvo puestos al mando de la milicia local, cinco hijos y dos hijas (32), de los que le sobrevivieron dos varones y dos hembras.

A la muerte de D. Francisco Soler de Cornellá, el 18 de enero de 1796, sus dos hijas, llamadas María Francisca y María Vicenta, eran todavía doncellas, siendo la última, en aquella fecha, menor de edad (es decir, de veinticinco años), lo mismo que su hermano D. Nicolás, caballero sanjuanista y alférez de navío de la Real Armada. También era por entonces alférez de navío el hermano mayor, D. Leonardo Soler de Cornellá y Juan, quien residía en Valencia (33), en donde había casado el año anterior con doña María Ana Saavedra y Jofré, quien también pertenecía a una familia de marinos. (34) El 2 de diciembre de 1800, don Leonardo se titulaba "teniente de fragata de la 
Real Armada y actual comandante de la bandera de marina de la ciudad de Valencia" (35), y parece que heredó el título de conde de Berbedel. (36)

La Iglesia, la orden de Malta y la milicia fueron, como vemos, colocaciones privilegiadas por los varones de Soler de Cornellá en el siglo XVIII, y sobre todo por los segundogénitos, que viendo pasar la mejor parte de los bienes familiares al hermano mayor, podían, con estas honrosas ocupaciones, "mantener el lustre y honor heredado" y la "distinguida estimación" de la casa, puntos que les resultaban muy sensibles. La documentación localizada nos muestra una familia bastante unida y concorde en hacer lo posible para mantener la posición y nombre de que gozaban, e incluso en mejorarlos. Ya hemos visto a frey $D$. Vicente favoreciendo a sus sobrinas con la cesión de bienes y rentas, aduciendo las mencionadas causas de "mantener el lustre" y "distinguida estimación" como motivo de su desprendimiento (37); el mismo argumento utilizará su sobrino D. Leonardo al consentir en ceder a su madre, D María Rafaela Juan, el usufructo de su finca en El Palombar, a cambio de quedar libres sus bienes de la pensión de viudedad instituída por su padre, en cuantía de cuatrocientos cuarenta y dos pesos. (38) En su testamento, dictado ante el notario Francisco Gil de Agulló el día 11 de enero de 1796, don Francisco Soler recuerda que los gastos para la profesión de su hijo Nicolás en la orden de San Juan de Jerusalén fueron satisfechos por su tío D. Pedro Soler y por su hermano D. Leonardo (39), señala que está gozando del vínculo fundado a su favor por su tío citado, el rico beneficiado D. Pedro Soler, y que a este vínculo su hermano D. Vicente agregó una almazara de vigas, obligándola en compensación a una renta de ochenta libras anuales instituída a favor de sus sobrinas. (40) Y después de su muerte, el canónigo D. Leonardo Soler abonó cien de las cuatrocientas libras que D. Francisco dispuso se gastasen en su funeral y sufragios (41), aliviando de este modo una herencia ya muy castigada por las deudas contraídas. En el mismo sentido, la viuda, doña María Rafaela Juan, contribuyó a dejar libre de cargas, en lo posible, el núcleo principal de los bienes familiares, incluyendo en su hijuela los gravados por censos, cargándose las deudas de la herencia, entre ellas las cuatrocientas libras que debían ser agregadas al vínculo que poseía en Játiva el mayorazgo de la casa, y aceptando el usufructo de la finca del Palombar a cambio de la pensión de viudedad instituída a su favor sobre bienes pertenecientes al vínculo fundado en 1740 por el abuelo Leonardo Soler. (42)

\section{Las bases económicas de una privilegiada posición.}

La base económica de la "distinguida estimación" de los Soleres de Cornellá radicaba, como era de esperar, en la propiedad de la tierra. La nobleza ilicitana de la época agrupa en su seno a los principales terratenientes, dueños además de las mejores tierras y también del agua de riego, bien escaso en la zona y precioso para la agricultura; mediante la práctica de las vinculaciones, este estrato de propietarios intenta proteger sus patrimonios de la disgregación. (43) Según las investigaciones de Pedro Ruiz Torres, el mayor número de vínculos laicos se crean en Elche en dos fases, durante la primera mitad del siglo XVII y en la primera mitad del siglo XVIII, especialmente entre $1740 \mathrm{y}$ 
1760. (44) Durante el primero de estos períodos, concretamente en 1629 , vinculará sus bienes Gaspar Soler de Cornellá y Chacón, vínculo que, al faltarle descendencia, pasará a través de su hermana Clara a los Vaíllo de Llanos. (45)

Los bienes de la rama familiar que estudiamos no serán vinculados, sin embargo, hasta el segundo período, concretamente hasta 1740. En el testamento que otorgaron el 25 de marzo de este año ante el notario Diego Mira, don Leonardo Soler y doña Vicenta Ros instituían un vínculo en cabeza de su hijo don Francisco Soler de Cornellá, sobre el quinto del total de sus bienes más un tercio de los restantes, según lo estipulado en las Leyes de Toro, vigentes en el País Valenciano desde la Nueva Planta. (46) Para el pago de las mejoras que hacían al citado don Francisco, señalaron los testadores la heredad situada en la partida de Benicaixer, que contaba con una casa dotada de bodega equipada, corrales y cisterna, e incluía ciento veinticuatro tahúllas y doce brazas de olivar, veintinueve tahúllas de viña, tres tahúllas siete ochavas y ocho brazas de frutales y ochenta y una tahúllas, tres ochavas y cinco brazas de tierra campa, todo ello bajo lindes cuya descripción permite suponer que esta extensión de tierra se encontraba agrupada. Es decir, algo más de veintidós hectáreas y media de tierra de cultivo, las que, sin hacer por sí mismas de su dueño un gran propietario (se situaría en el estrato intermedio de los propietarios del Elche de entonces), si constituyen una gran propiedad, más estimable todavía por estar perfectamente equipada para el cultivo. (47) Señalaron también ocho hilos de agua de la dula de Cuñera, que era la que regaba la citada heredad, y la mitad de la casa principal de los Soler de Cornellá en la parroquia de Santa María. (48) El testamento establece, como vimos, un riguroso orden sucesorio para el vínculo, del que excluye a todo religioso o religiosa profeso, aún en la orden de Malta, y clérigos ordenados "in sacris", para los cuales, caso de pertenecerles el vínculo y haberlo de renunciar por esta razón, se establece una renta anual de 50 libras. Se prevé también en el testamento el caso de falta de sucesión de todos los hijos de los aludidos, y también de falta absoluta de sucesión en el vínculo, en cuyo caso pasaría al clero de la iglesia de Santa María. (49)

Aunque no conocemos el conjunto total de las propiedades de don Leonardo Soler, no puede caber la menor duda de que las incluidas en este vínculo constituirían su núcleo principal, máxime atendiendo a que suponen prácticamente el total de los bienes que le atribuye el padrón realizado en 1752-1753, y que es como sigue, con las rentas anuales que dicho padrón atribuye a los bienes relacionados (50):

110 tahúllas de olivar en la partida de Benicaixer: 1.188 reales.

110 tahúllas de "mitjans" en la partida de Benicaixer: 264 reales

5 tahúllas de "plantats" en la partida de Benicaixer: 18 reales.

Una casa de campo en Benicaixer: 60 reales.

Una casa en la "plasuela de Santa María": 216 reales.

Una almazara en la calle de la Almórida: 180 reales.

Siete hilos de agua de la dula de Horts: 840 reales.

Y refuerza esta suposición el hecho de que don Leonardo y doña Vicenta tomasen 
toda clase de precauciones a fin de asegurar la sucesión de estas propiedades en manos de su hijo primogénito. A este fin, y para preveer el caso de que el valor de estos bienes excediese el importe de las mejoras del tercio y del quinto, comenzaron por establecer un orden de preferencias para su pago, que debía empezar por las tierras y agua relacionados "a proporción prudente", y dejando en último lugar su parte de la casa familiar. Sin embargo, para mayor seguridad, y previniendo el exceso de valor de dichos bienes dentro del conjunto de todos los suyos, tras disponer que el pago de las legítimas paterna y materna de don Francisco Soler se hiciera en el remanente que pudiere haber de las propiedades indicadas, ambos testadores disponían también que quedara del cargo de su hijo la satisfacción de los créditos que existían en su contra, abonándosele el valor del principal de dichas deudas en el resto que pudiere existir aún de la herencia mencionada, y que suponían el importe siguiente (51):

-dos censos al convento de Nuestra Señora de la Merced, el capital total de ambos 226 libras.

- un censo a la iglesia de Santa María, de capital 124 libras.

-un censo a la parroquial del Salvador, capital 106 libras.

-censo al patrimonio del marquesado de Elche, capital 200 libras.

-otro censo al mismo patrimonio, su capital 426 libras 15 sueldos.

Es decir, la respetable suma de 1.082 libras y 15 sueldos de capital principal, deudas que sabemos que, en el momento de su muerte, don Francisco, a pesar de las amonestaciones contenidas en el testamento paterno para que las amortizase (52), no sólo no las había redimido enteramente, antes al contrario, las había aumentado con nuevas cargas.

Además de los bienes raíces que don Leonardo Soler de Cornellá intentó (con éxito parcial, según creemos), transmitir a su hijo primogénito en el vínculo fundado en 1740, al que en su codicilo de 1762 intentó agregar los muebles y objetos de plata de su casa principal en la parroquia de Santa María, sabemos que poseía otros (53), de los cuales conocemos los siguientes:

-Trescientas tahúllas de tierra en los Carrizales de Elche, tierras pantanosas desecadas y colonizadas a partir de la década de 1730 por el marqués de Elche, quien las cedió en enfiteusis para su explotación. Estas tierras fueron legadas por don Leonardo Soler, en su codicilo de 20 de octubre de 1762, a su hijo don Leonardo Soler de Cornellá y Ros, ya presbítero entonces. (54)

-"Una cassa mezón (sic) y dos cassitas llamadas medianos, contiguas a d(ic)ha cassa mesón", situadas en Onteniente, el mesón en la plaza Mayor y las casitas en la calle de San Miguel, y "sujetas al Real Patrimonio", que fueron legadas a don Pedro Soler.

-Un molino de una muela, "intitulado el molino de San Jayme", con un huertecillo anexo, sujeto también al Real Patrimonio y sito en el barranco llamado de San Jaime, término de Onteniente; cuyo molino fue dejado en herencia a don Dionisio Soler. (55)

-La "herejad de La Hoya", comprada por don Leonardo al patrimonio del mar- 
quesado el 9 de octubre de 1715, y vendida posteriormente en fecha indeterminada. (56)

Digamos, por último, que el vecindario de la villa de Elche de 1730 atribuye a don Leonardo Soler propiedades por valor de 5.000 libras, lo que le colocaba en el undécimo lugar entre los nobles ilicitanos, y el décimosexto en el total de los propietarios de Elche. (57).

A excepción de las tierras carrizales y de las propiedades de Onteniente, no conocemos la situación jurídica exacta de los restantes bienes de don Leonardo Soler de Cornellá, pero podemos suponer que parte de ellos serían también tomados a censo enfitéutico del patrimonio del marquesado de Elche, bien que hubiesen llegado a los Soler por transmisión hereditaria o por compra del dominio útil de los mismos. Nos autoriza a suponer este punto el hecho de que, entre los censos que don Leonardo deja en 1740 del cargo de su hijo primogénito, figura como ya vimos, uno a favor del patrimonio del marquesado de Elche, que paga anualmente 14 libras, 4 sueldos y 6 dineros, a razón de 8 dineros por libra del capital y con facultad de su quitamiento de cien en cien libras, "que tomó a su cargo Gregorio Ortiz de Melchor" (58): cuyas condiciones y réditos responden exactamente a las que el señor de Elche, don Jorge de Cárdenas, impuso en 1611 a los nuevos pobladores que vinieron a establecerse en la villa después de la expulsión de los moriscos, y nos llevan a pensar que los Soleres habían adquirido el dominio útil de alguna propiedad, gravada con estas condiciones, del aludido Gregorio Ortiz. (59) Otros datos hay que abundan en este sentido, como los doscientos reales anuales que pagaba al patrimonio del duque de Arcos don Leonardo Soler, según el padrón de 1752-1753 (60); los 349 reales y 8 dineros que su hijo don Francisco abonaba en concepto de pechos, según el padrón de 1783 (61); o las quince tahúllas tres ochavas de olivar y un hilo de agua, bienes no vinculados que poseía el citado don Francisco "sugetos al patrimonio de este marquesado", y que encontramos incluídos en el inventario de sus bienes. (62) Por último, indiquemos que los Soler de Cornellá aparecen incluidos en una relación de la nobleza de Elche que se resistía a pagar pechos al señor en 1747-1748. (63)

Para la explotación de sus propiedades, los Soler de Cornellá buscaban, como es natural, las más ventajosas condiciones, en primer lugar agrupando las tierras de cultivo y acreciéndolas mediante arrendamientos: y así encontramos en 1743 al beneficiado don Pedro Soler de Cornellá tomando en arriendo por seis años, del clero de Santa María, ocho tahúllas de olivar en el "partido del Partidor Nuevo, bajo el riego de_Candalix", cuyas ocho tahúllas lindaban por un lado con tierras del propio don Pedro Soler, y por dos lados con fincas de su hermano don Leonardo Soler (64), cosa que, por otra parte, se nos antoja una muestra más de solidaridad familiar.

En cuanto a la forma efectiva de explotación, sabemos que practicaban el arrendamiento a corto plazo, en cuya forma eran explotadas las tierras que tenían tomadas en enfiteusis en los Carrizales de Elche, las cuales don Leonardo Soler cedió el uno de septiembre de 1756 por precio de cien libras anuales pagaderas por años vencidos y tiempo de seis, hasta igual fecha de 1762, a dos labradores analfabetos, Vicente Maciá 
de Irles y Baltasar Sánchez de Maciá, reservándose el arrendador "las taúllas (sic) que corresponden francas de contribuición (sic) de frutos", para construir una casa y otros fines. (65) Sin embargo, nos parece posible que una parte de las tierras propiedad de los Soler fuese explotada directamente, mediante jornaleros, o con aparceros, puesto que no sólo la heredad de Benicaixer, propiedad de don Leonardo Soler, y la del Palombar, de su hermano don Pedro, estaban dotadas de casa con instalaciones agrícolas, sino que sabemos por el inventario de sus bienes que don Francisco Soler, que vino a heredar ambas fincas, poseía en la última todo género de herramientas agrícolas y aperos de labranza, así como utensilios para la bodega, y también poseía cinco mulas y un mulo, tres burras y una yegua, susceptibles de ser utilizados en las labores del campo. (66) La posibilidad de una explotación de esta finca directamente o mediante aparcería es expresamente citada por don Leonardo Soler en la cesión de su usufructo que hace a su madre, doña María Rafaela Juan, el 25 de enero de 1796, a cambio de liberar su olivar del Partidor Nuevo de la renta de viudedad instituída por su padre. (67) Por último, y por su importancia para las explotaciones agrarias, cabe destacar la posesión de esos ocho hilos de agua, incluidos por don Leonardo Soler en el vínculo fundado en 1740, y cuya posesión, tan importante como la del suelo, estaba en la base de la prosperidad de los grandes propietarios ilicitanos del siglo .(68) Finalmente, debemos decir que, al menos en época de don Francisco Soler de Cornellá, de la administración de sus bienes se llevaba una contabilidad en libros, que eran cuidadosamente archivados por su propietario. (69)

De la primera a la segunda mitad del siglo va a producirse en el caudal del mayorazgo de los Soler de Cornellá un importante incremento, debido a la acumulación en manos de su titular de tres vínculos más del que ya, por su herencia paterna, poseía, y que extenderán su fortuna fuera del término de Elche, hacia tierras de Játiva y de la huerta de Valencia. Nosotros, sin embargo, nos limitaremos a analizar las propiedades poseídas en Elche, ámbito al que circunscribimos nuestra atención. Veamos cuáles eran estas nuevas propiedades.

En su testamento, otorgado el once de enero de 1796, pocos días antes de morir, don Francisco Soler de Cornellá declara que posee varios vínculos, que enumera, los cuales deben de recaer en su hijo primogénito (70), y que son:

-El fundado por sus padres, don Leonardo Soler de Cornellá y doña Vicenta Ros, "en el que recae la heredad de Benicaxer (sic) y la almasara de bigas de la calle de la Almórida, por agregación que hizo fr(ey) d(o)n Vicente, mi hermano, y seis ilos de agua de Cuñera". Vínculo que entró a poseer tras la muerte de su padre, ocurrida el cuatro de noviembre de 1762. (71)

-El fundado por su tío, el beneficiado de la iglesia de Santa María don Pedro Soler de Cornellá: "en él recaen la heredad de Palombar y demás fincas espesificadas en su testamento, exepto (sic) el bancal de Beniay"; este vínculo comprendía también tierras en la partida de Asprillas, y pasó a poder de don Francisco Soler de Cornellá tras la defunción de su tío, acaecida en fecha que no hemos podido determinar, pero que cabe situar entre 1777 y 1783 . (72) 
-"El que fundó d(o)n Joseph Soler de Cornellá y Martines de la Raga, mi primo hermano, de la alquería de Las Limeras, en la huerta de Valencia". Dicha alquería, que no formaba parte del vínculo fundado por don Guillem Ramon Anglesola a favor de don Tomás Soler de Cornellá y Anglesola, padre de don José, entró en poder de los Soleres de Elche tras morir sin sucesión don José Soler el 30 de noviembre de 1754. (73)

-"El que fundó d(oñ)a Vicenta March y Ros, mi prima hermana", que comprendía tanto bienes raíces como muebles, y que entró en poder de don Francisco Soler en diciembre de 1782. Esta herencia obligó a don Francisco a litigar en la Real Audiencia de Valencia, quedando finalmente resuelto el asunto con laudo arbitral de 15 de julio de 1776. (74)

Como vemos, los dos primeros vínculos eran los únicos que estaban ubicados en Elche, y los bienes incluidos en ellos constituían, como vamos a ver, el grueso de las propiedades ilicitanas de don Francisco Soler de Cornellá. Sin embargo, y respecto del primero de ellos, observamos que las disposiciones testamentarias de 1740 y 1762 no Ilegaron a cumplirse plenamente, puesto que ni la casa ni su ajuar estaban integrados en el vínculo de don Leonardo Soler, y tan sólo figuran en él seis de los ochos hilos de agua de riego que quiso incluir su fundador.

Para el análisis de la fortuna rústica de don Francisco Soler de Cornellá resulta de primerísima importancia el padrón conservado en el ayuntamiento de Elche en tres gruesos volúmenes gran folio, rotulado en el lomo del tercero "Rústica 1808", pero que en realidad corresponde al que Vicente Gozálvez Pérez, con sólidos fundamentos, considera elaborado en 1783. (75) En este padrón, los datos relativos a propiedades y rentas de don Francisco Soler de Cornellá son los siguientes (76):

D(o)n Fran(cis)co Soler

de Cornellá

Capital

Renta

Total renta

Casa calle de la Feria.

$16.900^{\prime \prime}$

650"

$650^{\prime \prime}$

Almasara calle de la

Almórida

$8.840^{\prime \prime}$

$340^{\prime \prime}$

340

Cuñera

Olivar

$1186 / 8$

98.958"

$25^{\prime \prime}$

$2.968^{\prime \prime}$

$18^{\prime \prime}$

Benicaxer

Tierra medianos

Viña

$1006 / 8$

$8.060^{\prime \prime}$

$4 "$

$403^{\prime \prime}$

$12 \quad 2.880^{\prime \prime}$

$12^{\prime \prime}$

$144^{\prime \prime}$

Igueras

$86 / 8$

$1.400^{\prime \prime}$

$8^{\prime \prime}$

$70^{\prime \prime}$

Candalix

Olivar

Medianos 
Palombar

Olivar

$$
99
$$

$82.500^{\prime \prime}$

$25 "$

$2.475^{\prime \prime}$

Asprillas

Tierra campa
Viña
Majuelo
Igueras
Plantados

Agua de dula, 15 ilos

430
34
24
30

Benicaxer

Pollancos
Viña

Tierra campa

Tierra loma

$\begin{array}{rr}4 & 1.120^{\prime \prime} \\ 4 & 960 " \\ 39 & 3.120^{\prime \prime} \\ 11 & 660^{\prime \prime}\end{array}$

11

$660^{\prime \prime}$

$\begin{array}{rrr}3 " & 12 & 1.505^{\prime \prime} \\ 12^{\prime \prime} & & 408^{\prime \prime} \\ 13^{\prime \prime} & & 312^{\prime \prime} \\ 8 " & & 240^{\prime \prime} \\ 14^{\prime \prime} & & 84^{\prime \prime} \\ 280^{\prime \prime} & & 4.200^{\prime \prime}\end{array}$

$\begin{array}{rr}14 " & 56^{\prime \prime} \\ 12 " & 48^{\prime \prime} \\ 4 " & 156^{\prime \prime} \\ 3 " & 33^{\prime \prime} \\ & 15.655^{\prime \prime}\end{array}$

\section{Baxas}

Censo a la s(eño)ra duquesa de Arcos

Otro al clero de S(an)ta María

Otro al del Salvador

Otro al S(an)to Ospital

Otro al conv(en)to de la Mer(ce)d

$$
\begin{array}{r}
60 \mathrm{r}(\text { eale)s } \\
50 " 10 " \\
31 " 20 " \\
6 " \\
30 " \\
53 " 16 " \\
349 " 8 " \\
\underline{581 " 6 "} \\
15.074 " 6 "
\end{array}
$$

Que le pasa de Fra(ncisc)o Antt(oni)o

Alamo y Cay(etan)o Candela

Benicajer (sic)Pollancos $2 \mathrm{t}$ (ahúlla)s 2/8

$$
\text { Igueras }
$$

Tierra

$\begin{array}{rr} & 20 " 45 " \\ 1 " & 8 " 8 " \\ 18 " & 4 " 72 " \\ & 15.199 " 6 "\end{array}$

Que le pasa de los her(edero)s de Diego Vives

Casa calle $\mathrm{S}(\mathrm{a}) \mathrm{n}$ Isidro

$150^{\prime \prime}$

Pasa

$15.349 " 6 " / / /^{30}$

Renta

15.349" 6" 
Que le pasa de Esperansa Vives

Casa calle $\mathrm{S}(\mathrm{a}) \mathrm{n}$ Isidro

Almasara calle $\mathbf{S}(\mathrm{a}) \mathrm{n}$ Isidro $\underline{200 "}$ $15.699 " 6 "$

Se le bajan $840 \mathrm{r}$ (eale)s por tres ilos de agua que ha/ vendido a carta de gracia a d(o)n Joaq(uí)n Perp(iñá)n

\section{$\underline{840 " “}$} $14.859 " 6 "$

Se le bajan $408 \mathrm{r}$ (eale)s por las tierras

pollancos/y plantados de Benicajer (sic), que ha ven-/ dido a d(o)n Josef Luis de las Casas Pasó a sus her(edero)s
408 " "

$14.451 " 6 "$

De las propiedades recogidas en este padrón, las cuatro primeras parcelas, situadas en las partidas de Cuñera y Benicaixer, y que totalizan doscientas cuarenta tahúllas y dos ochavas, corresponderían al vínculo fundado por don Leonardo Soler, mientras que las propiedades situadas en Palombar y Asprillas formarían la herencia del tío don Pedro.

Así pues, la extensión de tierra poseída por don Francisco Soler en el momento de hacer la primera estimación de sus rentas en 1783 (es decir, tras las "Baxas", que sitúan sus ingresos estimados en 15.074 reales y 6 dineros anuales), es de novecientas noventa y cuatro tahúllas y siete ochavas, que posteriormente se incrementará hasta mil quince tahúllas y una ochava. Esto, dentro del contexto ilicitano de su tiempo, le coloca en el grupo de los grandes propietarios, si bien no de los mayores: formaría parte, según Gozálvez, del grupo de quince propietarios (trece de la villa y dos del "Raval"), con propiedades entre setecientas veintinueve y mil cuarenta tahúllas, por encima de los cuales existen diecisiete propietarios de entre mil cuarenta y una y dos mil ochenta y una tahúllas, y cinco con más de dos mil ochenta y dos tahúllas. (77)

Ahora bien, a nuestro juicio, para determinar la posición económica de los propietarios, un factor mucho más ilustrativo que la extensión de tierra poseída según el padrón, es la renta estimada a cada propietario, puesto que considera, no sólo la propiedad fundiaria, sino la productividad de las posesiones, según el tipo de cultivos, así como el agua poseída, las instalaciones industriales (molinos, almazaras, etc.) y las casas y demás bienes. Las estirnaciones no son uniformes, ni para las casas e instalaciones industriales, ni para los cultivos de un mismo tipo, variando en éstos según zonas, si bien vemos que en todos los casos, el orden de valoración es uniforme, siendo los más apreciados los olivares, seguidos a distancia por los "pollancos" (olivares jóvenes) y "plantados" (arbolado), majuelo, viñas e higueras, por este orden. 
La consideración de las rentas nos permite observar que, si bien dentro de la nobleza, la posición económica de don Francisco Soler de Cornellá en su villa natal era una de las más firmes, sin embargo distaba mucho de las posiciones de cabeza, ocupadas por el tío de su esposa, don Bernardo Juan, a quien se estimaba una renta anual de 51.606 reales y 11 dineros, seguido por los dos homónimos don Joaquín Perpiñán de Sarabia y don Joaquín Perpiñán y Pasqual, con 31.943 reales 1 dinero y 28.403 reales y 6 dineros de renta, respectivamente. Viene luego un grupo de nobles, en el que ya se inscribe nuestro don Francisco, cuyas rentas van desde los 18.190 reales de don Pedro Santacília, pasando por los 15.286 reales 6 dineros de don Antonio Carbonell de Llanos, hasta los 12.077 reales 4 dineros de don Francisco de Paula Perpiñán y Miralles y los 10.961 reales 21 dineros de don José Vaillo de Llanos. Y finalmente, encontramos un grupo aún más numeroso que no alcanza los 10.000 reales, como don Antonio Lamurere ( 9.266 reales 18 dineros), don Antonio Ortiz de Rodrigo (9.095 reales), don Félix Desplá (8.480 reales 6 dineros) o don Pedro Miralles de Tárrega (2.766 reales). (78)

Sin embargo, el cénit de la fortuna es también el punto más próximo a su declinar. El padrón de 1783 muestra que el deseo expresado por el viejo don Leonardo Soler en 1740 , de que fueran redimidos los censos de que dejaba encargado a su hijo, sobre todo aquéllos de los que se respondía al marquesado de Elche, sólo se había cumplido parcialmente, y aún el heredero había gravado el patrimonio con nuevas obligaciones y alienaciones. El 30 de noviembre de 1773, don Francisco Soler vendía a carta de gracia abierta, por importe de 190 libras, medio hilo de agua de la dula de Cuñera al beneficio del título de San Francisco de Asís, instituído en la iglesia ilicitana de Santa María, y cuyo titular era entonces su hermano don Leonardo. (79) Pero el más ruinoso de los negocios de que tenemos noticia consistió en la compra por don Francisco a don Rafael Ortiz Martínez de Vera y Almodóvar, primer conde de Almodóvar, de una casa en la ciudad de Alicante, con otras dos accesorias, la cual, tasada en 8.600 libras, estaba sujeta a un censo exorbitante de 5.365 libras de capital y 160 libras 19 sueldos de pensión anual, a un interés del tres por ciento.(80)

Así las cosas, hacia los últimos años de su vida, don Francisco Soler comienza a realizar ventas importantes de sus bienes principales. El 2 de septiembre de 1793, juntamente con su hijo y heredero don Leonardo y con el fin de invertir el producto en la boda de este último, vendió a carta de gracia abierta y por precio de 1.100 libras, tres hilos de agua de la dula de Cuñera a don Joaquín Perpiñán y Pasqual, los que, a la muerte del comprador, aún no habían sido redimidos. (81) Posteriormente, entre esta fecha y la de su muerte, don Francisco volvió a vender, esta vez a don José Luis de las Casas, a quien cedió tierras "pollancos y plantados" en Benicaixer, que le supusieron una baja en sus rentas de 408 reales anuales. (82) Es decir, que en algo más de dos años, don Francisco Soler se desprendió de bienes que, estimados en renta según los padrones municipales, suponían aproximadamente el ocho por ciento del total de las que el municipio le calculaba, y que revisten mayor importancia por la calidad de los bienes vendidos. Cuando el 27 de julio de 1796 se hizo el inventario de los bienes libres de don Francisco Soler, encontramos la herencia gravada con deudas y pensiones elevadísimos, lo que, más que el hecho ficticio (aunque significativo) de que el valor 
de los bienes de la testamentaría iguale los créditos contra la misma, da idea de la precaria salud de un patrimonio que, en la década de 1835 a 1845 será definitivamente liquidado, y con el que desaparecerá de la sociedad de Elche el nombre de los Soler de Cornellá. (83)

\section{La presencia de los Soler de Cornellá en la vida local.}

De acuerdo con su rango social y su status, los Soler de Cornellá aspiraron a un papel destacado en la vida del Elche del siglo XVIII. La nobleza ilicitana de la época, relativamente poco numerosa, a pesar de tratarse de una gran villa (Townsend estimó que habrían en Elche unos doscientos caballeros, cantidad que vendría a representar aproximadamente el 1'2 por ciento del total de la población), había hecho desde antiguo patrimonio propio de la "defensa de la patria", y aspiraba en consecuencia al papel protagonista en la dirección de la sociedad local. (84) Según Pedro Ruiz Torres, en la centuria del setecientos, la pequeña nobleza se configura en Elche como una clase propietaria de tierras, que explota mediante arrendamientos a corto plazo y utilizando jornaleros, enriquecida con el cultivo, elaboración y comercialización del aceite y de la barrilla, productos destinados a ser exportados. Este autor considera estos métodos de explotación como capitalistas (sin que pueda decirse que lo sean plenamente), y atribuye a esta clase una mentalidad que califica de "preburguesa", buscando extraer el máximo beneficio de sus propiedades, si bien se valen todavía de instituciones del Antiguo Régimen, como la vinculación. Los nobles ilicitanos se encuentran situados en los puestos de control del municipio, tanto al frente del ayuntamiento como de las milicias locales, y forman un grupo tradicionalmente enfrentado a los señores de Elche. (85)

Así caracterizada, la nobleza de Elche tiene unos representantes arquetípicos en los Soler de Cornellá. Nada más comenzar el siglo, la familia entra de lleno a participar públicamente en los problemas del momento, tomando partido en la guerra de Sucesión. Su elección, común a otros miembros de su clase en Elche, no puede ir más abandonada de la Fortuna: el linaje en bloque (las dos ramas de que entonces constaba) abraza la causa de Carlos III de Austria. Las consecuencias fueron fatales. Una de las dos ramas se extinguió, puesto que los dos nietos del comendador de Montesa don Andrés Soler y Grañana, hubieron de exiliarse y murieron solteros: D. Juan Soler de Cornellá y Catalá falleció en Viena, en la corte del ya emperador Carlos VI, en fecha desconocida, mientras que don Carlos, su hermano, "después de su esclavitud, trabaxos, y pobreza", lo hizo en Génova en 1721. (86)

En cuanto a la rama principal que nos interesa, sufrió también intensamente con la contienda. De los hermanos de D. Pedro Soler de Cornellá y Malla, abuelo de nuestro canónigo, el único varón, D Antonio Soler de Cornellá, "a causa de las guerras ent(r)e Phelipe Quinto y Carlos Tercero, y después emperador de Alemania en el año 1706, murió en las cárceles de Murcia". (87) Su fallecimiento sucedió el 12 de octubre de 1707 y, como ya hemos visto, dejó heredero a su sobrino D. Pedro Soler. En cuanto a doña María Soler, hermana de ambos, murió así mismo en Murcia, el 3 de ju- 
nio de 1707 , y quizá podamos inferir una causa similar para su permanencia en esta ciudad.(88)

A lo largo del siglo XVIII, la familia Soler de Cornellá y el propio D. Leonardo, estuvieron en primera fila en todos los casos en que la nobleza ilicitana dio muestras públicas de su poco afecto a las casas de Aveiro y Arcos, que detentaron en el siglo XVIII el señorío de Elche. Tras la guerra de Sucesión, resurge la oposición antiseñorial desde fines de 1733, y entonces encontramos a don Leonardo Soler de Cornellá padre figurando entre los cabecillas de la nobleza levantisca que en 1735 fueron encarcelados por agitadores en el castillo de Alicante, al intentar inmiscuirse en el pleito que la villa llevaba, de un modo a su parecer demasiado pacífico, en contra de la duquesa de Aveiro. (89) Varios de ellos fueron luego embarcados a Málaga, con destino a los reales presidios, pero desde aquella ciudad, Felipe $\mathrm{V}$ los llamó a la corte, y posteriormente los puso en libertad. Sin embargo, esto no supuso escarmiento para los Soler. Treinta años después, el 12 de julio de 1765, el administrador en Elche del duque de Arcos comunicaba a éste cómo, al paso de su hermana la duquesa por Cartagena y Murcia, había sido desairada por la nobleza ilicitana en pleno, que no acudió a "cortejarla": según la relación de dicho criado, Pedro Arias, Ramón Miralles, Pedro Ortiz y su hijo Francisco Ortiz, cura de El Salvador, Joaquín Perpiñán, Juan Santacília, nuestro D. Leonardo Soler, entonces párroco de Almoradí, y su hermano Pedro Soler, acudieron a Murcia y a Cartagena, pero no solicitaron el honor de "ponerse a los pies" de la duquesa. Tamaña falta de consideración enfureció al duque, que ordenó a su administrador proceder al cobro inmediato de todas las deudas que dichos nobles tuviesen con él. (90)

Era entonces alcalde ordinario de Elche D. Francisco Soler de Cornellá, abogado, quien al año siguiente, con ocasión del sonado motín que tuvo lugar en la villa en abril de 1766, formó parte de la comisión que el día 23 de ese mes acudió a entrevistarse en Monforte con el juez Felipe Musoles, enviado por el Real Acuerdo de Valencia para hacerse cargo de la situación. Cuando el 29 del mismo mes, Musoles reunió en cabildo a 60 personas de distinción que habían sido capitulares, a fin de acabar con el motín, tras las alocuciones de los representantes de la nobleza, común y abogados, Francisco Soler de Cornellá tomó la palabra, diciendo que los pobres se habían levantado "porque se hallaban esclavizados y sumamente opresos por el Duque, y dixo gracias a Dios que ha llegado la hora de la Justicia". (91)

Por su parte, don Leonardo Soler de Cornellá, cura de Almoradí, tuvo también un destacado papel en la revuelta que, como eco de la de Elche, tuvo lugar en esta última población y otras de la comarca del Bajo Segura. A don Leonardo se atribuyeron las palabras, pronunciadas en una reunión, de que "en Almoradí no havía hombres, pues si los huviera, haziendo lo mismo que en Elche se quitaría la sissa y derecho de_molienda"; y así mismo, la reunión de las autoridades de la localidad que tomó la decisión de suprimir los derechos de la sisa de la carne y la molienda, con cuya acción se apaciguó el motín, tuvo lugar en su casa. (92)

En la represión de este motín en Elche tuvieron un destacado papel las milicias urbanas, que según Ruiz Torres eran un instrumento al servicio de la oligarquía propieta- 
ria . Dichas milicias, que en 1780 recibieron "goces y preeminencias" y "fuero militar y civil a 'os milicianos" (93), tenían a su frente a los nobles locales, que como parte de sus preeminencias, y alegando la función militar que se atribuían en justificación de sus privilegios, ostentaban los cargos de oficiales de dichas milicias. Estas fueron reconvertidas en 1794, según el nuevo aire de los tiempos, en "Compañía de Voluntarios Honrados". En este momento, encontramos a su frente, como "Comandante en jefe del batallón de Voluntarios Honrados de Estado del Partido de Xixona", a don Francisco Soler de Cornellá y Ros, tomando las medidas pertinentes para la instrucción de los milicianos. (94) A su muerte, en 1796, D. Francisco se titulaba "Theniente Coronel de Milicias Provinciales del Corregimiento de Xixona y comandante del mismo". (95) También formaba en estas compañías su hermano D. Vicente Soler de Cornellá, junto con otros nobles ilicitanos. (96)

Estas milicias urbanas fueron remozadas en 1808, ante la circunstancia bélica, procediendo en mayo de este año al alistamiento de los hombres entre 16 y 40 años. Y haciendo honor a la vocación militar de la familia, el 27 de junio siguiente, conducidos por D. Ramón Miralles de Imperial y D. Nicolás Soler de Cornellá y Juan, entró en AImansa la segunda división de alistados de Elche, a reforzar la segunda división del Ejército de Operaciones al mando de D. Pedro Buck y O'Donnell, mariscal de campo y comandante de la villa de Elche. Las milicias urbanas fueron dotadas en diciembre de 1808 de uniforme y abanderado, si bien la bandera no se acordó crearla hasta mayo de 1809 , la cual, elaborada en tafetán blanco, fue regalada por el teniente de fragata D. Leonardo Soler de Cornellá y Juan, y portaba a la Virgen de la Asunción, patrona de la villa, junto con las armas reales e ilicitanas, y la inscripción "Milicias urbanas de Elche". (97)

\section{"La desencia devida a su ilustre nacimiento". El tono de la vida en el medio local.}

En 1743 escribía D. Gregorio Mayans, a nombre de su primo don Antonio Pasqual, una justificación de la nobleza, que, puesta al frente de la genealogía de este último, debía explicar el origen de la misma y de las diversas clases de nobles; y al hablar de los caballeros, escribía el erudito valenciano:

"Se llaman equites, por la semejanza que tienen a los équites romanos; pues así como nadie podía ser equite romano sin que tuviesse quatrocientos mil sestercios,(...) de la misma suerte nuestros reyes no crean nobles sino a los que tienen suficiente renta para mantener el lustroso grado de la nobleza $i$, si no la tienen, se la dan, i este es el origen de los heredamientos, especialmente en tierras recientemente conquistadas" (98).

Esta realidad obligaba a los Soler de Cornellá a mantener un tono de vida acorde con su condición privilegiada, lo que, como hemos visto, era motivo de preocupación constante para los miembros de la familia. Vamos a intentar entrever en qué modo se mantenía el estado en la cotidianidad de la vida diaria.

En la demarcación parroquial de Santa María, zona en la que se concentraban las 
residencias de la nobleza ilicitana, se encontraba la casa familiar de los Soler de Cornellá, objeto de especial atención por parte del cabeza de familia D. Leonardo, que intentó repetidamente unir casa y ajuar al vínculo que fundó en el testamento que, junto con su esposa doña Vicenta Ros, otorgó ante el notario Diego Mira el 25 de marzo de 1740. (99) Dicha casa tenía su fachada principal a la calle de la Feria (actualmente Obispo Rocamora), y la trasera a la del Horno de Pomares (hoy Horno de la Ciudad), y lindaba con la del noble D. Bernardo Juan y con otra perteneciente al clero de Santa María. (100) Aún hoy día existe dicha casa, conocida popularmente en Elche como "la casa dels lleons", por los dos grandes tenantes que sostienen en la fachada el escudo cuartelado de los Soler de Cornellá, (101) que trae en el primero y cuarto un sol radiante, y en el segundo y tercero un león rampante. (102) Si la fachada (cuyo escudo presenta proporciones desmesuradas) resultaba lo bastante significativa respecto del rango y posición de los habitantes, no debían serlo menos los utensilios que contenía, en opinión del casi octogenario D. Leonardo, quien justificaba su agregación al vínculo fundado veintidós años antes en cabeza de su hijo primogénito "para que sirvan siempre a la correspondiente decencia de su posehedor". (103)

Según el inventario realizado en 1796, tras la muerte de D. Francisco Soler de Cornellá, la casa estaba dotada de "tinageros y almacenes" (104), como correspondía a la residencia de unos ricos hacendados, pero presentaba en lo restante de sus dependencias un carácter marcadamente urbano. El inventario citado muestra una diferenciación neta entre las zonas de servicio y las residenciales, en cuanto al mobiliario, si bien no especifica la distribución en superficie de las estancias. Con la ayuda de este documento, vamos a intentar obtener una impresión sobre el estado y la disposición de la vivienda principal de los Soleres de Cornellá, bien entendido que éste reflejará únicamente el estado de la mansión muy a finales del siglo XVIII, y que la forma de estar amueblada que recoge el documento nos parece que refleja las modas y concepto del arreglo interior de las viviendas que se difunden a partir del segundo cuarto de la centuria, y que suponemos que no corresponderían con el concepto de la decoración de la casa que debería de tener el viejo D. Leonardo Soler y Llanos, hombre que por su nacimiento en 1684 pertenece aún a la época anterior, más próxima a los usos del barroco.

Jean Sarrailh observa el juicio favorable que merecen a Jovellanos y Laborde determinadas personas que introducen en su tono de vida una elegancia de buen gusto y de finura en los hábitos del trato social, elogios que permiten suponer que quizá, tras el gusto refinado, exista una afición a las tendencias modernas en otros campos más complejos. (105) La decoración de la casa de los Soler de Cornellá permite inferir -siempre con la reserva propia de la índole que presentan las fuentes- ideas más bien de otro signo. La presencia de abundantes obras de arte, en su práctica totalidad de tema religioso, y entre ellas de "dos lienzos de los reyes", de una estampa con el retrato de Fr. Diego de Cádiz, y de dos pinturas de la Virgen de los Dolores, a cuya devoción instituyó un aniversario D. Leonardo Soler en su testamento de 1740 , y cuyo culto presentaba en Elche un carácter marcadamente nobiliario (106), se nos antojan más propias de tendencias de signo conservador: y a este respecto es interesante recordar que en su Aparato de eloqüencia, el canónigo Soler se muestra ferozmente contrario, 
no sólo al deísmo y a los "philosophes", sino también al regicidio, en forma bien explícita, y parece también que podamos ver en su obra ideas favorables a la unión entre el Altar y el Trono(107).

Centrándonos, sin embargo, en el ajuar de la casa, y sobre todo en el de las zonas residenciales que, por su mayor representatividad social, suponen una más consciente selección y reflejan por tanto con mayor fidelidad la penetración de las modas, cabe admitir que los Soler de Cornellá resultan, como cabía esperar de gentes de su posición, permeables a ellas. Si los criterios de la época recomiendan que las casas sean "confortables y agradables" y los espíritus ilustrados prestan atención a la comodidad tanto como a la estética en las suyas (108), la casa de los Soler se nos muestra amueblada con confort (aún con cierta prolijidad) y con lujo, que demuestran el interés y cuidado que se ponen tanto en la comodidad como en el tren de vida doméstico.

Y por lo que toca, en primer lugar, a las obras de arte que adornan la casa, que como ya hemos dicho eran mayoritariamente de tema religioso -cosa por otra parte común en la zona durante la época-, țan sólo hemos podido identificar entre ellas una "Virgen de la Leche" del discípulo de Juan de Juanes, Nicolás Borrás, obra "primorosa", al decir del padre Fr. Agustín de Arques, y de regular tamaño (109), que aparece en el inventario de los bienes de D. Francisco Soler tasada en 90 reales. (110) Otros cuadros que no hemos identificado debían quizá de prestar una nota de mayor animación en este ambiente de pintura religiosa, como "un lienzo del Triunfo de David, pintado_sobre madera", tasado en Il reales, o los "tres quadros de la Historia de Nabuco, pintados sobre cristal", en 90 reales, en los que a lo insólito del tema se une lo inusual del soporte; y también (¿nota exótica?), los "quatro paisitos pequeños, con dibujos de seda_de varios colores", importantes 10 reales y 17 dineros. (111) Todos ellos tenían marcos negros perfilados en dorado ("corla"), pues el inventario que manejamos presta tanta atención a los marcos como a los cuadros que protegen, y así, junto a los marcos "dados de negro y perfiles de corla", sabemos que los había dorados, negros, blancos y azules, azules y carmín, y algunos tallados. Vestían también las paredes de la casa algunas estampas enmarcadas, cuya tasación oscila entre dos y cinco reales, y cuyo tema, cuando aparece expresado, es siempre religioso; y espejos, de los que destaca, por su tamaño, uno de cuatro palmos de luz con marco de talla dorada, tasado en 200 reales. (112) En el ámbito de los objetos artísticos de finalidad decorativa (dejando de momento aparte los inventariados como "Plata"), entran también "un crusifixo de marfil y una pilita de plata para agua bendita", conjunto tasado en 200 reales, "una lámina_de cobre dorado con relieves de plata de N(ues)tra Señora de la Concepción", en 300 reales, y "un crucifixo de bronce con peaña dorada", en 20; cuyo conjunto parece integrar la totalidad de las muestras de escultura presentes en la casa. (113)

El sentido del lujo que reflejan plenamente los objetos hasta ahora relacionados tiene su continuación en los muebles que aparecen en el inventario, cuya ubicación, salvo algunos raros casos, no se indica. Sería excesivamente prolijo enumerarlos todos, y por ello tan sólo diremos que, a través del mobiliario relacionado, y a pesar del desorden en la enumeración de los objetos, parece que puede distinguirse, además de las alcobas y la cocina, un gran salón dotado de muebles suntuosos, más representati- 
vos, y un gabinete de trabajo. (114) Habría también una antesala, en la que estarían las "dos medias mesas de pino de a tres piez (sic), color azul, para antesala, a ocho r(eale)s cada una". (115) Pero del destino del resto de los muebles, salvo de aquellos cuyo uso lo hace obvio, poco puede decirse. Muy raramente se indica algo al respecto, como en el caso ya dicho de la antesala o del mobiliario de la cocina. (116) Cabe suponer que algunas de las abundantes rinconeras, medias mesas y veladores se destinarían quizá a corredores y descansillos de la escalera. La presencia de cinco catres verdes y otros tantos tablados de cama, además de dos "camones de pino dados de verde y los pies y cabeserillas de color de leche con perfiles dorados", más "una arquilla larga de nogal para guardar piesas de cama de colgadura", hace suponer la convivencia en la casa de una familia heril a la que sólo se menciona en el testamento de D. Francisco Soler de Cornellá y que utilizaría los muebles de inferior calidad. (117) Llama también la atención que aparezcan entre el mobiliario hasta ocho baúles forrados de cuero o piel con pelo, dos cofres forrados de cuero y badana, cuatro arcas, una arcaliza, tres arquillas, una sombrerera y una maleta. Junto con los dos guardarropas que se mencionan, la mayoría de estos elementos servirían para contener ropas u objetos, pero algunos de ellos debían destinarse a viajar, como la arquilla de coche que se cita, la maleta o una "cantina aforrada de baqueta", que también se menciona. (118)

Para la elaboración del mobiliario se utilizan maderas de nogal, cedro y albaricoquero, para los muebles de superior calidad, que alcanzan mayores tasaciones, y para los más inferiores morera y pino. Esta última madera es la más común y también la de menor estimación, por lo que cuando se emplea para muebles de más empeño comúnmente va teñida o pintada. La de morera tan sólo se utiliza para sillas, de las que aparece la sorprendente cantidad de ciento veintitrés grandes y doce pequeñas realizadas en este material. (119)

Sin embargo, no todo es lujo en la disposición de la casa de los Soler. Encontramos también, junto a los anteriores, muebles que, sin ser necesarios, atestiguan un deseo de comodidad utilitaria, como "una mesita de pino para dar de comer a los enfermos en la cama" o "un plato doble de peltre para calentar la comida". (120) El deseo de hacer confortable la casa viene demostrado por la presencia de una "cosina fransesa" (una chimenea de salón), destinada a asegurar la calefacción invernal, junto a los tradicionales braseros y el esterado en la estación fría. (121) Hay notas de modernidad, como la presencia de telas de indiana utilizadas para colchas y tapizados (122), la presencia de "una cómoda de albaricoquero con quatro cajones, y herrage dorado al fuego", o el uso de loza de Alcora o de dos medias vajillas inglesas, una blanca lisa y otra con flores verdes, las cuales alcanzan elevadas tasaciones. (123)

Por su parte, el inventario de la cocina y la casa da indicios de una alimentación refinada: encontramos útiles para el consumo de café y chocolate, tabaco y agua de nieve, y para elaborar dulces. (124) Y así mismo, el cuidado de la higiene da lugar a que buena parte de los utensilios de la cocina, sobre todo los relacionados con el agua, estén elaborados con cobre. (125)

Indiquemos finalmente que aparece inventariada una cierta cantidad de objetos de 
orfebrería, agrupados bajo el epígrafe "Plata", destinados básicamente al servicio de la mesa, cuyo importe en conjunto es de 3.947 reales: de entre ellos destacaremos "una selvilla (sic) de un pie con el escudo de las armas de los Soleres de Cornellá, su peso treinta y tres onzas". Como vemos, algunas de estas piezas habían sido labradas, o por lo menos marcadas, exprofeso, lo que es muestra elocuente de que en el ajuar y porte de la casa tenía también su importante papel el elemento de representatividad social, que era conscientemente buscado. (126) Y no menos demostrativo de elevada posición era el uso de coches, de los que figuran en el inventario de D. Francisco Soler de Cornellá "una caleza (sic) vieja", "un coche de moda" vendido en cuatro mil doscientos reales, y "una berlina con quatro acientos (sic)", tasada en dos mil reales. (127) Todos los carruajes aparecen entre los bienes muebles de la casa existente en la heredad que el difunto poseía en la partida del Palombar, en donde existía alguna estancia amueblada para habitación, y que, dotada de jardín y ermita, parece que pudo utilizarse para el recreo estival. (128) Alguno de los semovientes propiedad de don Francisco estaría destinado para arrastrar estos coches.

Las propiedades así inventariadas, aunque dan una idea de un tren de vida apropiado a la nobleza de una ciudad de la categoría de Elche en la época, no suponen, sin embargo, un ajuar excepcional, aunque sí a tono con los usos propios de la época. Por desgracia, los demás testamentos y divisiones que hemos hallado de la nobleza ilicitana de este periodo no recogen sus ajuares. Sin embargo, comparando el que nos ocupa con otros de personas más o menos coetáneas y de una posición similar, podemos observar que el inventario que manejamos, si bien refleja un mobiliario bastante cumplido, no resulta en abosoluto de calidad excepcional y, por el contrario, nos parece bastante corto en lo que toca a la presencia de objetos de platería. Y si bien en materia de carruajes la familia Soler se halla bien dotada, sin embargo el ganado de su propiedad no es tan abundante como para no tener que alternar las labores del campo con el tiro en los coches. (129)

En suma, la posición social de los Soler de Cornellá, que les venía impuesta por su pertenencia a la nobleza, les obligaba a mantener un tren de casa y un nivel de vida acordes. De ahí la constante preocupación por dotar a las mujeres solteras o viudas con rentas suficientes para mantener lo que definían como "la desencia devida a su ilustre nacimiento y distinguido estado". (130) Ya en el testamento de 1740, doña Vicenta Ros de Ursinos, en la única disposición que establece en solitario, mejora a su hija doña Josefa en 400 libras que debían de abonársele en censos. (131) Por su parte, en el de don Francisco Soler aparece la constante preocupación de que se paguen a sus hijas las cantidades que se les deben, procedentes de la testamentaría de su tío, el beneficiado don Pedro Soler y Llanos, o de rentas cedidas por su hermano frey don Vicente (132), quien ya vimos que además de estas dotaciones, cedió a sus sobrinas su parte en la herencia de su hermano, el canónigo don Leonardo. Y en cuanto a la viuda doña María Rafaela Juan, su marido don Francisco había instituído a su favor una renta anual de 442 pesos sobre sus olivares del Partidor Nuevo, previa licencia real, a pesar de que la citada viuda, en razón de los bienes de su dote y otros en que había sucedido, además de su parte en la testamentaría de su marido, vino a recibir en su hijuela, tras la 
muerte de aquél, bienes tasados en la respetable suma de 131.985 reales y 7 dineros. (133)

Otro aspecto de esta servidumbre social consistía en la necesidad de mantener y solemnizar de modo acorde los matrimonios y decesos, actos los más fundamentales de cara a la vida pública. La obligación del matrimonio conveniente conllevaba gastos a veces importantes: de los Soleres, sólo sabemos que la boda de su hijo D. Leonardo -futuro conde de Berbedel- con doña María Ana Saavedra y Jofré el 21 de mayo de 1795, obligó a don Francisco Soler a tomar en préstamo de D. Joaquín Perpiñán y Pasqual mayor, la suma de 11.000 reales, préstamo que se realizó en forma de venta a carta de gracia abierta (es decir, sin fecha de caducidad) de tres hilos de agua, un bien esencialísimo para los propietarios agrícolas ilicitanos, cosa que muestra hasta qué punto era fuerte esta necesidad de representación social. (134)

Y en cuanto a solemnizar los funerales, podemos observar al respecto una notable diferencia entre el viejo don Leonardo Soler y su hijo don Francisco. El primero, en su testamento dispuesto en 1740, veintidós años antes de su muerte (si bien no parece que sobre este aspecto introdujera modificaciones posteriores) se ocupó con cierta minuciosidad de las ceremonias de su sepelio, disponiendo para él y su esposa un funeral de cuerpo presente, con asistencia del clero de las tres parroquias de la villa y de los religiosos de los conventos de la Merced y de Santa Clara, y la celebración de dos mil misas rezadas, por mitad, minuciosamente repartidas entre las parroquias y conventos ilicitanos; comenzando antes de otra cosa por manifestar su voluntad de ser enterrados ambos cónyugues en su entierro propio, con el hábito franciscano. (135) Don Francisco, por su parte, se manifiesta de acuerdo con su padre en estos dos últimos puntos, pero en lo tocante a las ceremonias de su entierro, las deja enteramente al cuidado de sus albaceas, limitándose a señalar la cantidad de 400 libras, como importe total que deberá gastarse en su entierro, funeral y sufragios, sin especificar más detalles respecto a su celebración. (136)

Esta confianza en el criterio de los encargados de cumplir su testamento no creemos que deba de interpretarse como tibieza del sentimiento religioso, ni tampoco como signo de cicatería (aunque no parece ajena a esta limitación una preocupación económica), pues las mandas obligatorias del hijo cuadruplican el importe de las dejadas por el padre, sin contar las diez libras dejadas al hospital de la villa, institución de la que don Leonardo Soler y Llanos no hizo memoria. Bien sea señal de otro género de religiosidad, más austera y espiritualista, o quizá de apuros económicos, lo que parece translucirse es un deseo de renunciar a las vanidades superfluas en las celebraciones funerarias, las que, sobre conllevar grandes gastos, daban lugar a que los miles de misas encargadas a las parroquias y altares en los legados píos, acumuladas a otras anteriores, terminaran por no decirse, por auténtica imposibilidad material. Sin embargo, este deseo de limitar el aparato no era general entre sus conciudadanos del mismo estamento, y así vemos que el noble don Bernardo Juan, vecino de D. Francisco Soler y tío de su esposa, muerto el trece de julio de 1797 , en su testamento de ese mismo año, dispuso se celebrasen por su alma dieciocho aniversarios y dos mil misas, además de legar ocho mil libras al hospital y veinte a la redención de cautivos. (137) 
De un modo o de otro, a partir de ahora los Soler de Cornellá comienzan a declinar en el pequeño mundo de la nobleza de la ciudad de Elche, en la que brillaron durante trescientos años. Transladado el primogénito de D. Francisco a Valencia y establecida la viuda en Alicante, la venta de algunas medianas propiedades y, sobre todo, del agua de riego, bien preciadísimo, el cuidado del difunto en limitar sus expensas funerarias, las crecidas deudas que soporta su testamentaría, son indicios de que los Soler de Cornellá han empezado su eclipse en su ciudad natal, en la que su alejamiento y la venta de sus tierras durante la década de 1835-1845 supondrá su definitivo ocaso dentro del círculo de las élites urbanas del Elche del siglo XIX. Su último brillo será en 1887, cuando el erudito Aureliano Ibarra incluya a don Leonardo Soler, canónigo de la catedral de Orihuela, entre los ilicitanos ilustres cuyo nombre se acordó inscribir en las paredes del salón de sesiones de la casa consistorial. (138)

\section{NOTAS}

(1)- Vid. Ramon Baldaquí Escandell: "La reforma de la predicación en el XVIII valenciano: Leonardo Soler de Cornellá", en Anales Valentinos. Revista de Filosofía y Teología, año XIII (1987), número 25, págs. 87 a 137.

(2)- Joaquín Lorenzo Villanueva y Astengo: Vida literaria de don Joaquín Lorenzo Villanueva, o memoria de sus escritos y de sus opiniones eclesiásticas y políticas, y de algunos sucesos notables de su tiempo (Londres, A. Macintosh, 1825); vol. I, pág. 3:

"Concluida mi carrera de estudios en la primavera de 1777, y graduado primero de maestro en Artes, y luego de Doctor de Teología a expensas del M. R. arzobispo don Francisco Fabián y Fuero, protector de los estudiosos, siendo de edad de 18 años pasé a Orihuela, al concurso de la canongía magistral de aquella santa iglesia. En ella fue provisto don Leonardo Soler, antiguo cura de la iglesia parroquial de San Salvador de Elche (sic), muy elocuente predicador, formado por buenos modelos, autor de una oratoria sagrada bien escrita, fruto del estudio de largos años. Correspondo con $\tan$ justa memoria a los oficios de sincera amistad e intimidad que me prestó hasta la muerte".

(3)- Archivo Parroquial de Santa María de Elche (en adelante, APSM) sig. 146/1: Legajos de noticias genealógicas, sub voce Solers de Cornellá, pp. 1 y 2. Se trata de un cuaderno de 23 páginas, escrito en 1766 (pág. 14). Vid. Joaquín Serrano Jaén: "Un noble il.licità del segle XVII: Gaspar Soler i Chacón (1592-1629)", en Festa d'Elx, 42, 1990, pág. 40.

(4)- Un hijo y un nieto de este Gaspar, llamados Juan Soler y Malla y Gaspar Soler y Chacón respectivamente, fueron habilitados a las Cortes de 1604, y Juan Soler fue nombrado uno de los 52 pagadores de las galeras. Esta línea se extinguió a causa de la muerte prematura de los hijos de este Gaspar Soler Chacón, Ilamados Juan Bautista e Isabel, por lo que su importante fortuna pasó a través de su hermana Clara Soler Chacón, casada con Isidoro Vaillo de Llanos, a este último linaje. Al estudio de esta rama de los Soler de Connellá está dedicado el excelente estudio de Joaquín Serrano Jaén, citado en la nota anterior. 
(5)- APSM, sig. 146/1, Legajos de noticias genealógicas, cit, pp. 9, 15, 23. Vid. el árbol genealógico adjunto.

(6)- APSM, sig. 146/1, loc. cit., pág. 2: “A este Juan Soler, hijo de Pedro, obtuvo licencia de mos(én) Luis Soler, vicario general, para que pueda hazer un carnero para su entierro junto al altar de S(a)n Sebastián, en la yglecia parroquial de S(an)ta María de Elche, el qual entierro alinda de levante en el altar de S(a)n Sebastián, de poniente, junto al banco que está serca del altar mayor, de mediodia en el choro de dicha yglecia, de tremontana en la pared del altar mayor; y por dicha gracia, el dicho Juan Soler ofrece dar 6 l(ibra)s. Consta todo lo dicho por escritura recibida por Ginés Miralles, not(ari)o, en 2 de junio de 1518. Vid. Joaquín Serrano Jaén, op. cit., p. 40. En 1603, doña Ana Grañana, esposa de D. Juan Soler de Cornellá y Daroca, expresa en su testamento el deseo de ser enterrada "en S(an)ta María, en el enterro de los Soleres": vid. APSM., sig. 146/1, loc. cit., p. 9.

(7)- Vid. Joaquín Serrano Jaén, op. cit. pág. 40; y el árbol genealógico adjunto. Como puede observarse, los Soler observaron la práctica del matrimonio múltiple, entroncando con determinados linajes por enlaces dobles, práctica quizá destinada a asegurar la permanencia en las familias de los patrimonios: este es el caso de los uniones entre los Soler y los Malla en la generación de los hijos de Juan Soler y Portes, o con los Vaíllo de Llanos, en el último cuarto del siglo XVII. La práctica continúa durante el siglo XVIII, y así vemos un doble enlace, los de don Tomás Soler y doña Josefa Martínez de la Raga, en 1702, y el de la sobrina del primero, doña Josefa Soler, con don José Martínez de la Raga, en 1746.

(8)- APSM, sig. 146/1, loc. cit., pp. 6-7. Vid. Serrano. Jaén, op. cit., pp. 40-41.

(9)- APSM, sig. 146/1, loc. cit., pp. 1 y 10.

(10)- APSM., leg. 146/1: Legajos de noticias genealógicas, loc. cit., p. 23. Este D. Andrés Soler murió siendo sacerdote.

(11)- Ibid., p. 23. Vid. también Barón de Finestrat (D. José Luis de la Guardia y Pascual del Pobil): Nobiliario alicantino (Alicante, Instituto de Estudios Alicantinos, 1983), p. 314.

(12)- APSM., leg. 146/1, loc. cit., pp. 14-15. Barón de Finestrat, op. cit., p. 314. Este D. Pedro Soler, casado con doña María Malla, murió en 1686.

(13)- APSM, leg. 146/1, loc. cit., pp. 15-16. Barón de Finestrat, op. cit., p. 314. Archivo Municipal de Elche (en adelante AME): Sigilotheca lllicitana, sección sexta, número 7.

(14)- APSM., leg. 146/1, Legajos de noticias genealógicas, loc. cit., p. 18. Barón de Finestrat: Nobiliario..., p. 315.

(15).- Vid. Carme Pérez Aparicio y Joan Brines Blasco: "La vinculació al País Valencià: origen, transmissió i disolució dels vincles d'En Guillem Ramon d'Anglesola", en Homenatge al doctor Sebastià García Martínez (València, Conselleria de Cultura, Educació i Ciència, 1988), pp. 246-248. Este D. Tomás Soler y Anglesola casó en Valencia con doña Josefa Martínez de la Raga el día 24 de enero de 1702, y tuvo un hijo, D. José Soler de Cornellá y Martínez de la Raga, que murió soltero, causa por la cual una parte de su herencia pasó a sus parientes ilicitanos, como más ađelante tendremos ocasión de ver. APSM., leg. 146/1, loc. cit., pág. 18. Barón de Finestrat: Nobiliario..., p. 315.

Notemos que, entre la relación de los confiscados del Reino de Valencia a consecuencia de la guerra de Sucesión, aparece un D. Tomás Soler, a quien se interviene la exigua renta de 15 libras. (Debo este dato a la amabilidad de la señorita Carmina Serra Mengual, quien actualmente prepara su memoria de licenciatura sobre el tema de las confiscaciones tras la guerra de Sucesión). 
(16)- APSM., sig. 146/1, loc. cit., pp. 16 y 21. Vid. Vicente Gozálvez Pérez: El_Bajo Vinalopó. Geografía agraria. (Valencia, Departamento de Geografía, 1977), pp. 157-158.

(17)- Vicente Gozálvez Pérez, en su libro La ciudad de Elche. Estudio Geográfico (Valencia, Departamento de Geografía, 1976), p. 63, ubica la casa familiar de esta rama de los Soleres de Cornellá, extinguida con la guerra de Sucesión, que lindaba con el huerto de los mercedarios, en la zona de la actual plaza ilicitana de la Merced; circunstancia que propició el que don Juan Soler de Cornellá y la comunidad mercedaria se interesasen por la edificación conjunta de unas casas en 1688. En opinión del Dr. D. Rafael Navarro Mallebrera, archivero municipal de Elche, dicha casa pudo estar ubicada en el lugar que posteriormente ocupó la que fue propiedad del erudito ilicitano D. Juan Gómez Brufal.

(18)- Barón de Finestrat (Don José Luis de la Guardia y Pascual del Pobil) y Dalmiro de la Válgoma y Díaz-Varela: Real Compañía de Guardias Marinas y Colegio Naval. Catálogo de pruebas de caballeros aspirantes (Madrid, Instituto Histórico de la Marina, 1943-1956), tomo IV, p. 88, números 4.160 y 4.161 .

(19)- APSM. leg. 146/1, loc. cit., p. 18: "Y este d(o)n Leonardo fue el que hizo el carnero, en su entierro, en S(an)ta María de Elche, y el primero que se enterró". Sobre la construcción de la nueva iglesia de Santa María, que es la actualmente existente, vid. Rafael Navarro Mallebrera: Los arquitectos del templo de Santa María de Elche (Alicante, Caja de Ahorros Provincial de Alicante, 1980), y también Inmaculada Vidal Bernabé: La escultura monumental barroca en la diócesis de Orihuela (Alicante, Excma. Diputación Provincial de Alicante, 1981), págs. 2936, 105-110, 146-147, 154-155.

(20)- AME., Protocolos de Francisco Gil de Agulló 1796, fols. 34v-35.

(21)- Esta ubicación es la que atriburye a dicha casa el padrón de 1752-1753, dato que, como todos los relativos a dicho padrón, nos ha sido amablemente facilitado por el Dr. D. Joaquín Serrano Jaén.

(22)- APSM., sig. 146/1, Legajos de noticias genealógicas, loc. cit., p. 18. Don Vicente nació el 19 de febrero de 1740, vid. Barón de Finestrat: Nobiliario..., p. 315.

(23)- AME., Protocolos de Diego Mira 1740, fols. 91-92: "es nuestra voluntad fundar, como fundamos en quanto pueda subsistir, vínculo fideicomisso de rigoroza agnación y/191v primogenitura, de forma que siempre haya de succeder el primogenito descendiente de varón, por manera, que si el d(ic)ho d(o)n Fran(cis)co Soler, nuestro hijo, falleciesse sin hijos varones de legítimo y carnal matrimonio, pase dicho vínculo a d(o)n Dionisio Soler Cornellá y Ros, nuestro hijo, y si éste falleciesse sin hijos varones de legítimo y carnal matrimonio, pase dicho vínculo a d(o)n Pedro Soler Cornellá_y Ros, nuestro hijo, y si éste falleciesse sin hijos varones de legítimo y carnal matrimonio, passe d(ic)ho vínculo a d(o)n Leonardo Soler Cornellá y Ros, también nuestro hijo, y si éste falleciesse sin hijos varones de legítimo y carnal matrimonio, pase d(ic)ho vínculo a dio in Vicente Soler Cornellá y Ros, nuestro hijo, y en dicha conformidad a los demás hijos nuestros(...)y en el caso de fallecer todos sin hijos varones de legítimo y carnal matrimonio, pase d(ic)ho vínculo a d(oñ) a Josepha Soler Cornellá y Ros, nuestra hija, y/192 descendientes de ésta, y sus hijos, siguiendo siempre los primogénitos y varones, tomando los apellidos de Soler, Cornellá y Ros (...)". Vid. Barón de Finestrat: Nobiliario..., p. 315, para el matrimonio de doña Josefa; al respecto, cabe decir que el primogénito varón, don Francisco, había nacido en 1726 .

(24)- Barón de Finestrat, op. cit., p. 315. Pedro Ruiz Torres: "Los motines de 1766 y los inicios de la crisis del «Antiguo Régimen»", en Bartolomé Clavero, Pedro Ruiz Torres y F. J. Hernández Montalbán: Estudios sobre la revolución burguesa en España (Madrid, Siglo XXI, 1979), p. 69. 
(25)- Barón de Finestrat-Dalmiro de la Válgoma: Real Compañía de Guardias Marinas..., t. II, p. 97, número 1.201; y t. IV, p. 88, números 4.160 y 4.161. El barón de Finestrat, en su Nobiliario..., p. 315, indica que fue también teniente del Regimiento de Dragones de la Reina.

(26)- AME., Protocolos de Francisco Gil de Agulló 1796, fols. 36v, 281v-282v. La toma de posesión de dicha encomienda fue el 1 de mayo de 1784.

(27)- Todos los datos sobre la vida de Soler hasta ahora expuestos, en Ramón Baldaquí Escandell; "La reforma de la predicación en el XVIII valenciano...", pp. 93-97, 101-102, 135-137. AME, Protocolos de Francisco Gil de Agulló 1773, fol. 154.

(28)- Vid. José Montesinos Pérez Martínez y Orumbella: Compendio histórico_oriolano (manuscrito en la colección de la Caja Rural Central de Orihuela), tomo VII, p. 452 y 464-465.

(29)- AME. Protocolos de Francisco Gil de Agulló 1796, folio 239:

"En la villa de Elche, a primero día del mes de mayo del año mil setecientos noventa y seis: ante mi el escrivano y notario público y testigos infraescritos, fueron presentes d(oñ)a María Fran(cis)ca Soler de Cornellá, de estado honesto, mayor de los veinte y cinco años, por sí, y d(oñ)a María Rafaela Juan y Ximenes de Urrea, como curadora de las personas y bienes de d(o)n Nicolás y d(oñ)a María Vicenta Soler, sus hijos y del difunto d(o)n Fran(cis)co Soler de Cornellá, su marido, de esta vecindad (...) y dixeron: que en el día veinte y siete de abril último falleció en la ciudad de Orihuela el señor d(o)n Leonardo Soler de Cornellá, canónigo magistral de la santa iglesia catedral de la misma, tio y cuñado respective de las otorgantes, sin haver echo disposición alguna testamentaria, perteneciendo por lo mismo sus bienes abintestato a fr(ey) d(o) $n$ Vicente Soler, comendador de Ambel en la orden de San Juan de Jerusalem, y a los sobredichos d(oñ)a María Fran(cis)ca, d(o)n Nicolás y d(oñ)a María Vicenta Soler, y d(o)n Leonardo Soler, alferes de navio, como hijos y herederos del mencionado d(o)n Fran(cis)co Soler, hermano entero del d(o) n Leonardo difunto". En este mismo documento se menciona la formación de inventario de los bienes del difunto previo a la división de los mismos; sin embargo, a pesar de haber buscado dicho inventario en los archivos de protocolos de Orihuela y Elche, no hemos podido dar con él.

(30)- Vid. Barón de Finestrat: Nobiliario..., pp. 158-159, 315. Pedro Ruiz Torres; Señores y propietarios. Cambio social en el sur del País Valenciano, 1650-1850 (Valencia, Institución Alfonso el Magnánimo, 1981), pp. 331-333. Copia certificada de la partida de bautismo de don Nicolás Juan, bautizado en Novelda el 8 de abril de 1708, en AME. Sigilotheca Illicitana, sección tercera, número 21.

(31) - AME., Cabildos de 1752, sin foliar ni paginar; cabildo de 18 de noviembre de 1752.

(32)- Barón de Finestrat: Nobiliario..., p. 315.

(33)- AME., Protocolos de Francisco Gil de Agulló 1796, fols. 35v, 38, 54. Los dos hermanos Soler de Cornellá ingresaron juntos en la Real Compañía de Guardias Marinas el 28 de septiembre de 1785. Vid. Barón de Finestrat-Dalmiro de la Válgoma: Real Compañía de Guardias Marinas..., t. IV, p. 88, núms. 4.160 y 4.161.

(34)- Vid. Barón de Finestrat-Dalmiro de la Válgoma: op. cit., tomo IV, p. 166, núm. 4.318.

(35)- Pedro Félix Jover Ibarra: Tipología notarial del archivo municipal de Elche en el siglo XVIII: protocolos del escribano D. Pedro Pasqual de Ganga (1786-1800). Memoria de licenciatura inédita, dirigida por el Dr. D. Enrique Giménez López; Universidad de Alicante, septiembre 1982. Fol. 571: poder de D. Leonardo Soler de Cornellá y D. Clara Saavedra a favor de D. José Useros y D. Francisco Cepriano (sic) Ortega. Elche, 2 de diciembre de 1800.

(36)- Barón de Finestrat: Nobiliario..., p. 315.

(37)- AME., Protocolos de Francisco Gil de Agulló 1796, fol. 282. 
(38)- AME., Protocolos de Francisco Gil de Agulló 1796, fols. 54v-55:

"Otrosí: así mismo declara y otorga que por quanto el nominado d(o)n Fran(cis)co Soler,//55 su difunto padre, impetró real cédula para constituir la pención de quatrocientos quarenta y dos pesos, o la cantidad que fuese, con título de viudedad o para alimentos, a la referida d(oñ) a María Rafaela Juan, sujetando a su responsión y pago el rento (sic) del olivar del Partidor Nuevo, huerta de esta villa, contenido en los vinculos en que ha succedido el otorgante; $y$ haviendo tratado sobre este punto y combenido con su señora madre en liberar esta finca de dicha consignación y trasladar la afección o hipoteca a la heredad llamada del Palombar, cita en este término, compuesta de casa, bodega, graneros y demás servidumbres rústicas, hermita, jardín, tierras plantadas de olivar, viña, igueral y otros árboles y las de pan sembrar, sobre cuya propiedad fundó vínculo d(o)n Pedro Soler de Cornellá y Llanos, tío del otorgante, en que igualmente ha sucedido: para que la mencionada d(oñ)a María Rafaela pueda legitimamente disponer del usufruto de esta finca, llevándola de su cuenta, o dándola a renta, medias, partido o como le paresca y más la combenga, desde luego cede, renuncia y transpasa su aprovechamiento y dominio útil a favor de la misma, en pago de la expresada cantidad de alimentos consedidos a su actual estado de viuda, haciéndola favor, gracia y obcequio de el más valor que excediese a la citada consignación, en atención a los naturales respetos que la deve y a los extraordinarios beneficios que la ha merecido y espera recibir el otorgante de su maternal afecto; como también para que pueda más cómodamente mantener la desencia devida a su ilustre nacimiento y distinguido estado, y proporcionar la de sus hijos, hermanos del otor(gant)e".

(39)- AME., Protocolos de Francisco Gil de Agulló 1796, fol. 37v.

(40)- AME., Protocolos de Francisco Gil de Agulló 1796, fols. 35v, 37.

(41)- AME., Protocolos de Francisco Gil de Agulló 1796, fols. 386-386v.

(42)- AME., Protocolos de Francisco Gil de Agulló 1796, fols. 54v-55, 388v-389v.

(43)- Vid. Pedro Ruiz Torres: Señores y propietarios..., pp. 214-221.

(44)- Ibid., pp. 221-222.

(45)- Joaquín Serrano Jaén: "Ưn noble il.licità del segle XVII: Gaspar Soler i Chacón", p. 53.

(46)- Vid. al respecto, Enrique Gacto: "El marco jurídico de la familia castellana. Edad Moderna" en Historia, instituciones, documentos, número 11, 1984, pp. 56-59.

(47)- Para la equivalencia métrica de las tahúllas en Elche y sobre las cuestiones de la propiedad agraria en la época, vid. Vicente Gozálvez Pérez: El Bajo Vinalopó. Geografía agraria, pp. 150-156.

(48)- AME. Protocolos de Diego Mira 1740, fols. 90-91v:

"Otrosí: los d(ic)hos d(o)n Leonardo Soler de Cornellá y d(oñ)a Vicenta Ros, consortes, usando de la facultad q(ue) el d(e)r(ech)o nos permite, en la forma que más bien pueda subsistir, mejoramos en el tercio y remanente del quinto de todos nuestros bienes, drechos (sic) y acciones, a d(o)n Fran(cis)co Soler de Cornellá y Ros, nuestro hijo primogénito, y para el pago de $d(i c)$ ha mejora, le destinamos el hazienda que tenemos y posehemos en el término de esta villa, partido de Benicaixer, baxo el riego de Cuñera, compuesto de casa de morada, corral de gando, sisterna, bodega con doce botas de ochenta cántaros cada una, de ciento veinte y quatro taúllas (sic) doze brasas de olivar, $/ /^{*} v$ ve inte y nueve tahúllas de viña, tres taúllas (sic) siete ochavas y ocho brasas de frutales, y ochenta y una taúlla (sic), tres ochavas, cinco brasas de tierra campa, o las taúllas (sic) que fueren. Baxo los lindes todo, de levante, con tierras de dio in Jayme Ortiz, tierras de Salvador Fenoll y de los Tárregas, brasal de Cuñera enmedio; de poniente, con olivares de Ceva, olivares y pollancar de d(o)n Jayme Ortiz; de mediodía, con olivares de Sebastián 
Segovia y olivares de los herederos de Joseph Masiá y vereda; y de trasmontana, con tierras del $d(i c)$ ho d(o)n Jayme Ortiz, brasal de Cuñera enmedio. Y assímismo destinamos para el pago de $d($ ic)has mejoras ocho ilos de agua de la dula de Cuñera, $q($ ue) tenemos y posehemos escritos en el libro maior del repartimiento de aguas de esta villa, y son los siguientes: dos ilos escritos en $d(i c)$ ho libro maior, en la plana primera, título Noche; un ilo en d(ic)ho libro y plana, título Dia; otro ilo en d(ic)ho libro, en la primera plana, segunda llana, titulo Noche; otro ilo en dicho libro, $/ /^{*}$ en la primera llana, segunda plana, título Día; otro ilo en d(ic)ho libro, en la segunda llana, primera plana, título Día; otro ilo en el referido libro, en la quarta llana, primera plana, título Día; medio ilo en d(ic)ho libro, en la quinta, primera, título Día; y otro medio ilo en d(ic)ho libro, en la quinta, segunda, título Día. Y assimismo destinamos para el pago de $d($ ic)has mejoras la cassa (sic) principal de habitación que tenemos y posehemos en la población de esta villa, parrochia de S(an)ta María, dividiéndose d(ic)ha casa por la primera pared de ella que se mira a la izquierda del primer salón, dexando el remanente de ella, eo habitación anexa, para los demás nuestros hijos a quienes cupiere. De cuyas mejoras del tercio y remanente del quinto es nuestra voluntad fundar, como fundamos en quanto pueda subsistir, vínculo, fideicomisso de rigoroza agnación y/"'v primogenitura, de forma que siempre haya de succeder el primogénito descendiente de varón (...)".

Sobre el riego en Elche en la época, vid. Vicente Gozálvez Pérez: El Bajo Vinalopó..., pp. 201-215.

(49)- AME. Protocolos de Diego Mira 1740, fols. 91v-93v. Caso de recaer en el clero de Santa María, debía de utilizarse el producto del vínculo para sufragios por el alma de los fundadores y el culto de la Virgen de los Dolores: vid. más adelante, el texto transcrito en la nota 106.

(50)- Estos y los demás datos que ofrecemos sobre el padrón de 1752-53, nos han sido amablemente proporcionados por el doctor D. Joaquín Serrano Jaén, excelente conocedor del Elche de la época, cuya tesis doctoral, aún inédita, estudia las cuestiones relativas a la agricultura y la propiedad de la zona en el tránsito del Antiguo Régimen a la época moderna.

Sobre los padrones ilicitanos del siglo XVIII, vid. Vicente Gozálvez. Pérez: El Bajo Vinalopó..., pp. 145-150.

(51)- AME. Protocolos de Diego Mira 1740, folios 93v-95v.

Cabe destacar que los débitos expresados en este testamento son prácticamente los mismos que recoge para don Leonardo Soler el padrón de 1752-1753, cuyo conocimiento debemos igualmente a la gentileza del doctor D. Joaquín Serrano Jaén, y que son los siguientes (expresados en pensiones anuales):

-Al patrimonio del duque (de Arcos): 200 reales.

-Al convento de la Merced: 67 reales, 18 dineros.

-A Santa María: 37 reales, 5 dineros.

-Al Salvador: 31 reales, 12 dineros.

-Al Hospital de la Caridad: 6 reales, 8 dineros.

Relacionando los capitales expresados por don Leonardo Soler y doña Vicenta Ros en su testamento, con los réditos expresados por el padrón de 1752-53, resulta que los censos a las instituciones religiosas importan un interés aproximado del tres por ciento, salvo el del hospital, cuyo capital no conocemos. Caso aparte son los dos censos al duque de Arcos, de los que sabemos por el testamento citado que el primero pagaba 10 libras anuales sobre un capital de 200 (lo que supone el cinco por ciento de interés), y el segundo, del que no se expresa el capital, satisfacía "a razón de ocho dineros por libra (...) en cantidad de catorze libras, quatro sueldos y seis 
dineros" (folios 94v-95), lo que supone un principal de 426 libras 15 sueldos, y un interés del 3'33\%.

La suma de todas las pensiones expresadas en el padrón importaba un total de 342 reales y 19 dineros, de los que 200 iban a las arcas del duque; sin embargo, por cuanto sabemos por su testamento que don Leonardo reconocía abonar anualmente al patrimonio del marquesado de Elche un total de 24 libras, 4 sueldos y 6 dineros, es decir, 242 reales y 6 dineros, cabría suponer que entre 1740, fecha del testamento, y la de confección del padrón, don Leonardo consiguió el quitamiento de 126 libras y 15 sueldos del capital del segundo censo que pagaba al duque (importante 426 libras y 15 sueldos), reduciendo así la pensión en cuatro libras, cuatro sueldos y seis dineros anuales (es decir, 42 reales y 6 dineros) y dejándola en 20 libras anuales, que se corresponden con los 200 reales que recoge el padrón de 1752-53; salvo siempre que exista error por alguna de las partes. Esto es perfectamente posible en el caso de que dicho censo fuese por la tenencia de alguna propiedad establecida por el patrimonio del Marquesado de Elche, en las cuales se percibía el rédito expresado de ocho dineros por libra sobre el valor estimado de la propiedad, con facultad de redimir este censo incluso parcialmente, en cantidades que no bajasen de cien libras, accediendo también parcialmente a la propiedad: lo que expresa también el testamento de don Leonardo Soler, cuando dice que este segundo censo lo posee "con facultad de su quitamiento y de poderlo hacer de cien en cien libras" (fol. 95). Sobre las condiciones de los establecimientos en el marquesado de Elche, vid. Antonio Gil Olcina: "Las escrituras de establecimiento y venta a carta de gracia de las haciendas de moriscos en el marquesado de Elche", en Cuadernos de Geografia, número 24, 1979, pp. 27-38.

(52)- AME. Protocolos de Diego Mira 1740, folio 95v:

"Otrosí: encargamos al dicho d(o)n Fran(cis)co Soler, nuestro hijo, y demás succesores en el vínculo formado, procuren el quitamiento de los debitorios y censos que llevamos referidos, y especialmente los que respondemos al patrimonio de su ex(celenci)a de este marquesado".

(53)- Para conocer los bienes de los Soler de Cornellá disponemos, además de los padrones ilicitanos de $1752-53$ y 1783 y de los ya citados testamentos de D. Leonardo Soler de Cornellá de 25 de marzo de 1740 y de su hijo don Francisco Soler de Cornellá de 11 de enero de 1796, y las referencias contenidas en el inventario, división y tasación de bienes de este último, realizado el 27 de julio de 1796, de un codicilo otorgado por cion Leonardo Soler el 20 de octubre de 1762 ante el notario de Elche Francisco Gil de Agulló. Sabemos, por referencias contenidas en el citado codicilo de 20 de octubre, que don Leonardo otorgó otros dos con fechas de 8 y 10 de abril de 1751, ante el notario Juan Gil, del que no se han conservado los protocolos correspondientes en el archivo municipal de Elche, a pesar de que aparecen en un inventario realizado por el archivero Pedro Ibarra Ruiz a fines del siglo XIX o principios del actual. Tampoco hemos hallado el testamento del beneficiado D. Pedro Soler, del que la noticia genealógica de los Soler de Cornellá conservada en el archivo parroquial de Santa María de Elche nos informa que fue dictado ante el notario Carlos Pasqual en fecha desconocida: de este notario se conservan protocolos en el archivo municipal ilicitano correspondientes a los años 1735 a 1780 . Y por último, digamos que, a pesar de haberlos buscado en los archivos de protocolos de Elche y Orihuela, no hemos podido encontrar la escritura de constitución de patrimonio que don Leonardo Soler debió de realizar antes de ordenarse de presbítero, ni el inventario de sus bienes realizado tras su muerte abintestato.

(54)- AME. Protocolos de Francisco Gil de Agulló 1762, fols. 88-88v. El doctor don Joaquín Serrano Jaén tuvo la gentileza de indicarnos que los padrones ilicitanos del XVIII atribuyen a los Soler de Cornellá 290 tahúllas de tierras marjales, situadas "en la segunda cuesta de las barracas". Estas tierras fueron legadas por don Leonardo, en su codicilo de 10 de abril de 1751, a 
sus hijos don Vicente y don Leonardo conjuntamente, disposición modificada luego en el codicilo de 1762, en el cual se indica además expresamente de dichas tierras "que me son concedidas en enfiteusis por el patrimonio de su exelencia (sic), que serán trecientas tahúllas, o las que fueren, baxo los lindes de su cabreve" (fol. 88).

(55)- Cabe suponer que no serían los reseñados todos los bienes de don Leonardo Soler, puesto que antes de comenzar la relación de los legados que hace a sus hijos en propiedades que posee en Onteniente, da a entender que disfruta otras: pero cuáles fueran, no lo sabemcs, si bien es de suponer que debían de venirle por herencia de su esposa, doña Vicenta Ros de Ursinos y Barberá.

(56)- AME. Protocolos de Francisco Gil de Agullo 1796, fol. 387. El tenor de la partida del inventario de los bienes de don Francisco Soler de Cornellá que recoge el censo que gravaba esta propiedad, y que luego, al venderse como libre, quedó el censo pesando sobre los restantes bienes de don Francisco, parece que podría dar pie a pensar que la venta fue obra de este último. En todo caso, tal heredad no aparece en la relación de sus bienes que ofrece el padrón ilicitano de 1783, vol. I, fols. 158v-159. El beneficiario del censo era el hospital ilicitano de la Sangre de Cristo.

(57)- Vid. Pedro Ruiz Torres: Señores y propietarios..., pp. 214-215.

(58)- AME. Protocolos de Diego Mira 1740, folios 94v-95:

"Assímesmo (sic): un debitorio eo censo, su capital ducientas (sic) libras, y de pensión anua dies libras, que con facultad de su quitamiento, respondemos al patrimonio de su ex(celenci) a de este marq(uesa)do; como también el capital correspondiente a la pensión anua que a razón de ocho dineros por libra respondemos a dicho patrimonio, en cantidad de catorze libras, quatro sueldos y seis dineros, o lo que fuere, en razón de censo que tomó a su cargo Gregorio Ortiz del/ss Melchor, con facultad de su quitamiento y de poderlo hacer de cien en cien libras."

(59)- El artículo ya citado de Antonio Gil Olcina: "Las escrituras de establecimiento y venta a carta de gracia de las haciendas de los moriscos en el marquesado de Elche" en Cuadernos de Geografia, número 24, 1979, pp. 27-38, expone las condiciones del establecimiento de los repobladores de Elche tras la expulsión de los moriscos, y la facultad que adquirían de poder alcanzar la plena propiedad de sus fincas, pagando el precio en que fueron estimadas, incluso a plazos, siempre que éstos no fueran menores de cien libras, así como la facultad de dividirlas o vincularlas; reproduce también un modelo de las escrituras de establecimiento, que se subscribieron utilizando un formulario impreso al efecto.

El otro censo que, según su testamento, pagaba don Leonardo al marquesado de Elche, con capital de 200 libras y 10 de pensión anual (es decir, a razón de 12 dineros por libra, lo que equivale al $5 \%$ de interés), no encontramos que responda claramente a las condiciones de los establecimientos ilicitanos, cuyos censos, según Gil Olcina, eran de 6 y de 8 dineros por libra.

(60)-Vid. supra, nota 51, sobre los censos que pagaba don Leonardo Soler al marquesado de Elche.

(61)- AME. Rústica 1808, vol. I, folio 158v.

(62)- AME. Protocolos de Francisco Gil de Agulló 1796, folio 386.

(63)- Vid. Pedro Ruiz Torres: Señores y propietarios..., p. 123.

(64)- AME. Protocolos de Carlos Pasqual 1743, folios 27v-28v:

"En la villa de Elche, a veinte y tres de henero de mil setesientos quarenta y tres años. ante mi el es(criba)no p(úbli)co y testigos infraescritos, paresió mos(sén) Thomás Lloret, presb(íte)ro, vesino de d(ic)ha villa y en n(omb)re de síndico que es del rev(eren)do clero de $S$ (an)ta Maria de la misma (consta de d(ic)ho nombram(ient)o ante el presente es(criba)no, su 
fecha en dies y siete de diz(iem)bre del año pasado mil setensientos quarenta y dos), dixo: que dava, y dió en arrendam(ien)to a d(o)n Pedro Soler de Cornellá, vesino de la mesma villa, ocho tahúllas de olivar que d(ic)ho rev(eren)do clero tiene y posehe en esta jurisdicción, partido del Partidor Nuevo, bajo el riego de Candalix, que linda por levante con brasal e igueras del d(octo)r Juan Baup(tis)ta Travalón, de pon(ien)te con medianos q(ue) eran de d(o)n Leonardo Soler,_de mediodía con olivar del referido d(o)n Pedro Soler, y de transm(onta)na con olivar que era de d(ic)ho d(o)n Leonardo Soler; por tiempo de seis años presisos, q(u)e empesaron a correr y contarse en el día y fiesta de Navidad del expresado año mil setesientos quarenta y dos en adelante, y feneserán en otro tal día y fiesta de Navidad del año que viene mil setesientos quarenta y ocho. Por presio cada uno de ciento quatro reales, moneda corr(ien)te, los quales ha de pagar en una paga, al fin de cada un año de d(ic)ho arrendam(ien)to; el qual le haze bajo las condiciones sig(uien)tes: (...)" (folio 27v).

(65)- AME. Protocolos de Francisco Gil de Agulló 1756, folios 104v-105v.

(66)- Para la heredad de Benicaixer, vid. más arriba, la nota 45; para la del Palombar, AME. Protocolos de Francisco Gil de Agulló 1796, folios 383v-384v. Los semovientes, en folios $384 \mathrm{v}-385$.

(67)- AME. Protocolos de Francisco Gil de Agullo 1796, fol. 54v-55. Vid. supra, el texto reproducido en la nota 38 .

(68)- Sobre la importancia histórica del riego en Elche, vid. Vicente Gozálvez Pérez: El Bajo Vinalopó..., pp. 201-210. Señalemos que, según datos suministrados por el doctor don Joaquín Serrano Jaén, sabemos que el padrón de 1752-1753 atribuye tan sólo a don Leonardo Soler la propiedad de siete hilos de agua "de la dula de Horts".

(69)- Referencias a esta contabilidad en el testamento de don Francisco Soler de Cornellá y en el inventario de sus bienes: vid. AME. Protocolos de Francisco Gil de_Agulló 1796, folios $36-36 \mathrm{v}, 37 \mathrm{v}, 386 \mathrm{v}-387$. Al final de su vida, la administración de los bienes de don Francisco corría a cargo de su omnipresente esposa y de su apoderado, don Ignacio Ruiz de Lope y Bru (loc. cit., folio $37 \mathrm{v})$.

(70)- AME. Protocolos de Francisco Gil de Agulló 1796, folios 35v-36:

"Ytt(em): Por quanto estoy al presente poseyendo varios vínculos, es a saber: el fundado p(o)r mis padres d(o) n Leonardo Soler de Cornellá y Llanos y d(oñ)a Vicenta Ros, de las mejoras del tercio y quinto de sus herencias, en el que recae la heredad de Benicaxer (sic) y la almasara de bigas de la calle de la Almórida, por agregación que hizo fr(ey) d(o)n Vicente, mi hermano, y seis ilos de agua de Cuñera. Más, el vínculo fundado por d(o)n Pedro Soler de Cornellá y Llanos, mi tío: en él recaen la heredad de Palombar y demás fincas espesificadas en su testamento, exepto (sic) el bancal de Beniay, que lo vendió dicho mi tío años antes de su muerte a d(o)n Félix Desplá. Otrosí, el que fundó d(o)n Joseph Soler de Cornellá y Martines de la Raga, mi primo hermano, de la alquería de Las Limeras, en la huerta de Valencia. Y última222mente, el que fundó d(oñ)a Vicenta March y Ros, mi prima hermana, en el qual recahen todos los bienes rahices y muebles q(u)e se expresan y contienen en las escrituras de laudo $y$ sentencia arbitral que se publicó por los jueces compromisarios d(o)n Christóval Tarazona y $d(o) n$ Antonio Berenguer, abogados, ante Joaquín Pastor, escrivano, en Valencia, a quince de julio del año mill/so setecientos setenta y seis, y de restitución de bienes otorgada por d(o)n Joseph Jofré, viudo de d(oñ)a Joaquina March, usufructuraria de dicho vínculo, en favor de mí el testador, ante el mismo escrivano Joaquín Pastor, en el mes de diciembre de mil setecientos ochenta y dos. Y como todos estos vinculos, después de mis días, recahen en mi hijo primogénito, el expresado d(o)n Leonardo Soler de Cornellá y Juan, como a verdadero e indubitado succesor que es en ellos, declárole así y quiero que, como a tal, sea puesto en la real y corporal po- 
seción (sic), seu quasi, de todos ellos y bienes de que se componen, para que los posea durante su vida con la bendición de Dios y mía".

(71)- Vid. APSM. sig. 146/1, Legajos de noticias genealógicas, loc. cit., página 18.

(72)- Vicente Gozálvez Pérez: El Bajo Vinalopó..., p. 158, indica que de las 734 tahúllas poseídas por don Pedro Soler de Cornellá, 596 estaban situadas en Asprillas. Aunque la genealogía de los Soleres de Cornellá, en el legajo 146/1 del archivo parroquial de Santa María de Elche, afirma que don Pedro Soler testó ante el notario Carlos Pasqual (p. 21), no hemus podido hallar su testamento, a pesar de haber revisado la serie continuada de protocolos del mismo que se custodia en el archivo municipal ilicitano y que abarca desde 1735 hasta 1784. En cuanto a la fecha de su muerte, la hemos fijado basándonos en el legado que, según don Francisco Soler afirma en su testamento (AME. Protocolos de Francisco Gil de Agulló 1796, fol. 36) hizo don Pedro a sus cuatro hijos menores, don Nicolás, don Pedro (muerto en 1783), doña María Francisca y doña María Vicenta (nacida en 1777), lo que indica que dichos cuatro hijos estaban vivos en aquel momento: don Pedro Soler gozó, pues, de una lóngeva existencia, puesto que había nacido en 1689 (APSM. loc. cit.). Vid. Barón de Finestrat: Nobiliario..., p. 315.

(73)- Vid. Joan Brines Blasco y Carme Pérez Aparicio: "La vinculació al País Valencià: orígen, transmissió i dissolució dels vincles d'En Guillem Ramon Anglesola", en Homenatge al Dr. Sebastià García Martínez (Valencia: Conselleria de Cultura, Educació i Ciència de la Generalitat Valenciana, 1988), pp. 244-246.

(74)- El 27 de junio de 1776 escribía desde Orihuela don Leonardo Soler de Cornellá a don Juan Antonio Mayans, pidiéndole que recomendase la causa de su hermano Francisco, que iba a Valencia "con motivo de cierto asumpto pendiente en la R(ea)l Sala", ante su sobrino don José. Vid. en la biblioteca municipal de Valencia, fondo Serrano Morales, legajo 7.283-71, número 16.445 .

(75)- Vid. Vicente Gozálvez Pérez: El Bajo Vinalopó..., pág. 146, nota 291, indica que en el acta municipal de 30 de agosto de 1837 y en la de 10 de abril de 1838 se indica que los libros padrones del catastro de Elche aún entonces vigentes se formaron en 1783. Los libros del padrón rotulado Rústica 1808 , aunque no coinciden en su disposición física con la descripción que hace Vicente Gozálvez del padrón de 1783, sin embargo, la disposición interna de los datos, caligrafía cuidada, etc. sí responden a las características descritas por este autor (vid. El Bajo Vinalopó..., pp. 145-147). Además, el análisis interno de la partida consagrada a don Francisco Soler de Cornellá obliga a situar su primera redacción después de 1777 (puesto que aparecen a su nombre las propiedades de su tío don Pedro Soler), y antes de 1793 (fecha en que se realizó la venta de tres hilos de agua a don Joaquín Perpiñán que recoge una de las actualizaciones del libro). Los dos primeros libros de que consta el padrón están desencuadernados y en muy mal estado, el tercero, mejor conservado, presenta en el lomo una nota manuscrita en la que puede leerse Rústica 1808 (de ahí el título que les damos). La pérdida de las primeras y últimas hojas de los tres volúmenes impide mayores precisiones.

Los libros recogen a los propietarios de Elche ordenados por su nombre de pila, salvo los caballeros y doctores, que lo están por su tratamiento, y así figuran agrupados. Las diversas partidas presentan múltiples actualizaciones posteriores a la primera confección del padrón, la mayoría no clatadas, pero algunas, que sí lo están, permiten ver que el libro estuvo en uso durante todo el primer cuarto del siglo XIX. Al estar las actualizaciones sin datar, para establecer comparaciones sobre propiedades o rentas nos limitaremos a la primera suma de rentas netas, que pensamos refleja la situación de los propietarios en 1783 , en el momento de la confección del padrón, prescindiendo de las actualizaciones.

(76)- Ofrecemos a continuación una transcripción de la partida correspondiente a don Fran- 
cisco Soler de Cornellá en el padrón ilicitano de 1783 (AME. Rústica 1808, vol. I, folios 158v159). Los datos que ofrece este padrón se estructuran en cinco columnas: en la primera, se indican las propiedades rústicas, urbanas e industriales, especificando para las agrarias la partida rural del campo de Elche en la que se ubican, y la explotación a que se destinan las distintas parcelas; la segunda columna, que carece de encabezamiento, especifica la extensión de cada una de las parcelas de explotación en tahúllas y ochavas, siendo la equivalencia de la tahúlla en Elche de $953 \mathrm{~m}$ " La tercera columna, "Capital" indica el valor estimado de cada una de las propiedades catastradas; la cuarta columna, "Renta", la renta anual estimada por unidad, o en las propiedades agrarias, por cada tahúlla, expresada en reales corrientes y dineros. Y finalmente, la última columna, "Total de renta", expresa el total de renta anual estimada por cada propiedad, resultado de multiplicar la cifra de la columna "Renta" por el número de unidades de cada uno de los bienes estimados, o bien por la extensión superficial de las propiedades agrarias, y se expresa también en reales corrientes y dineros. Cabe indicar que las expresiones "tierra de medianos" y "medianos" indican, según información que debemos al doctor don Joaquín Serrano Jaén, "huerta alejada de la villa", "plantados" equivaldría a "arbolado", "tierra campa" es, según creemos, terreno destinado a la siembra, mientras que "tierra loma" ignoramos qué indica con precisión, aunque a tenor de la valoración que se hace de ella podemos colegir que se trata de algún tipo de terreno marginal.

(77)- Vid. Vicente Gozálvez Pérez: El Bajo Vinalopó..., págs. 143-145.

(78)- Todos son datos del AME. Rústica 1808, volumen I: don Bernardo Juan, fols. 154 $154 v$; don Joaquín Perpiñán de Sarabia, fols. 152-152v; don Joaquín Perpiñán, fols. 165-166v; don Francisco de Paula Perpiñán y Miralles, fols. 161-161v; don Pedro Santacília, fols. 169-170; don Josef Vaíllo de Llanos, fols. 174-174v; don Antonio Lamurere, fol. 164; don Antonio Ortiz de Rodrigo, fol. 157v; don Félix Desplá, fols. 167-167v; don Pedro Miralles de Tárrega, fol. $158 \mathrm{v}$.

(79)- La venta en AME. Protocolos de Francisco Gil de Agulló 1773, folios 154-155.

(80)- Mención de esta compra y circunstancias en AME, Protocolos de Francisco Gil de Agulló 1796, fols. $385-385 \mathrm{v}, 389$.

(81)- Vid. más arriba, las partidas de don Francisco Soler y don Joaquín Perpiñán en AME. Rústica 1808, loca cit., y Pedro Félix Jover Ibarra: Tipología notarial del archivo municipal de Elche en el siglo XVIII..., folios 331-332, número 687, en donde se regesta la escritura de venta a carta de gracia de los tres hilos de agua, protocolizada ante el escribano don Pedro Pasqual de Ganga. Sobre el destino del dinero obtenido de la venta, AME. Protocolos de Francisco Gil de Agulló 1796, folio 37v. La transmisión de los tres hilos de agua a los herederos de don Joaquín Perpiñán, en AME. Rústica 1808, vol. I, folios 158-158v, s. v. "[V(iu)da de] d(o)n Antonio Tárrega".

(82)- AME. Rústica 1808, folio 159. A juzgar por el importe de la baja registrada, creemos que las tierras vendidas deben de ser las recogidas en las dos últimas partidas del padrón de 1783 bajo la denominación "Benicaixer", una inmediatamente antes y otra inmediatamente después de la partida de "Baxas", cuyas rentas, sumadas, montan 418 reales y en extensión total 79 tahúllas y dos ochavas.

(83)- Vid. Pedro Ruiz Torres: Señores y propietarios..., pp. 326 y 364-365. Sin embargo, el Barón de Finestrat, en su Nobiliario alicantino, pág. 316, recoge la presencia en Elche de miembros de este linaje hasta 1941.

(84)- Pedro Ruiz Torres: Señores y propietarios..., pp. 72-75; 194-195. Joaquín Serrano Jaén. "Un noble il.licità del segle XVII...", pp. 42-46. 
(85)- Pedro Ruiz Torres. Señores y propietarios..., passim, especialmente los capítulos 9 , 13, 14. Buen resumen de las ideas de este autor en su trabajo "Los motines de 1766 y los inicios de la crisis del «Antiguo Régimen»", ya citado, pp. 64-70.

(86)- APSM., sig. 146/1, Legajos de noticias genealógicas, loc. cit., p. 15, números 35 y 36.

(87)- APSM., sig. 146/1, Legajos de noticias genealógicas, loc. cit., p.16. Este D. Antonio Soler de Cornellá pleiteó contra el vínculo fundado por D. Nicolás Caro, que había recaído, por disposición testamentaria del fundador, en la Virgen de la Asunción, patrona de la villa.

(88)- APSM., loc. cit., pp. 16-17, número 39. Doña María Soler, viuda de D. Jorge Santacília, era casada en segundas nupcias, celebradas en 1688, con don José Vaillo de Llanos y Vaíllo de Llanos, caballero de Montesa y gobernador de Elche (cuya hermana doña María era a su vez casada con D. Pedro Soler de Cornellá y Malla) y que guardaba parentesco próximo con D. Juan Vaíllo de Llanos, destacado austracista y primer conde de Torrellano. También era primo segundo del conde de Torrellano D. Leonardo Soler de Cornellá y Vaillo de Llanos, padre de nuestro canónigo. Vid. Barón de Finestrat: Nobiliario alicantino..., pp. 341-343. Joaquín Serrano Jaén: "Un noble il.licità del segle XVII: Gaspar Soler i Chacón", p. 41.

(89)- Vid. Pedro Ruiz Torres: Señores y propietarios..., p. 194.

(90)- Vid. Pedro Ruiz Torres: "Los motines de 1766 y los inicios de la crisis del «Antiguo Régimen»", p. 69.

(91)- Ibidem, p. 90.

(92)- Vid. Jesús Millán y García-Varela: Rentistas y campesinos. Desarrollo agrario y tradicionalismo político en el Sur del País Valenciano, 1680-1840 (Alicante, Instituto Juan Gil-Albert, 1984), pp. 345-346. José Miguel Palop Ramos: Hambre y lucha antifeudal. Las crisis de subsistencias en Valencia (siglo XVIII) (Madrid, Siglo XXI, 1977), pp. 165-167.

(93)- Pedro Ruiz Torres: Señores y propietarios..., p. 340.

(94)- AME., Protocolos de Pedro Pasqual Ganga 1794. Obligación de 31 de octubre de 1794 por la que Diego Antón de Pons y Diego Pasqual de Pons se obligan a servir de tambor mayor y pífano, respectivamente, y a dar instrucción de tales, en el Batallón de Voluntarios Honrados de Estado del Partido de Jijona, del que es comandante don Francisco Soler de Cornellá. Vid. Pedro Félix Jover Ibarra: Tipología notarial del archivo municipal de Elche en el siglo XVIII..., fols. 373-374.

(95)- AME., Protocolos de Francisco Gil de Agulló 1796, fol. 34v: testamento de D. Francisco Soler de Cornellá y Ros, 11 de enero de 1796.

(96)- Pedro Ruiz Torres: Señores y propietarios..., pp. 340-341.

(97)- Pedro Ruiz Torres: Señores y propietarios..., pp. 353-354. Alejandro Ramos Folqués: Historia de Elche (Elche, ediciones Picher, segunda edición 1987), p. 202.

(98)- Gregorio Mayans y Siscar: "Manual genealógico de Antonio Pasqual y García, generoso" en Obras completas, 1. Historia (Valencia, Ayuntamiento de Oliva, 1983), p. 406. Anteriormente escribe: "Manteniéndose pues las riquezas en la familia, se vive sin necesidad del propio trabajo con esplendor y dependientes; se adquiere el grado de ciudadano según nuestras antiguas leyes: deste nace la hidalguía, de la hidalguía la generosidad, i assi se han hecho generosas muchas familias, que no pudiendo manifestar conocido y público principio de su nobleza, le tienen legitimamente usurpado con la quasi posessión de muchos años o siglos." (pp. 405406)

(99)- AME., Protocolos de Diego Mira 1740, fols. 89-96v; Protocolos de Francisco Gil de Agulló 1762, fols. 88-89v: en este último protocolo se contiene el codicilo otorgado por D. Leo- 
nardo Soler el 20 de octubre de 1762, trece días antes de su muerte, en el cual intentaba agregar la plata y ajuar de su casa al vínculo fundado veintidós años antes.

(100)- AME. Protocolos de Francisco Gil de Agulló 1796, fols. 385v-386. A la muerte de D. Francisco Soler de Comellá en 1796, dicha casa fue tasada en la respetable cantidad de 37.873 reales y 12 dineros, si bien no era la más importante de las poseídas por el difunto.

(101)- Debo esta información al señor D. Juan Castaño García, archivero del Patronato Nacional del Misterio de Elche, gran conocedor de las cosas ilicitanas, que tuvo la gentileza de atender mis consultas con la amabilidad y generosidad que le caracterizan.

(102)- El escudo de Soler de Cornellá recuerda poderosamente al que las Trovas de mossên Jaime Febrer atribuyen al caballero Raimundo de Soler (troba 478 en la edición de D. Joaquín María Bover: Palma de Mallorca, imprenta de Pedro José Gelabert, 1848, página 255; cito por la edición facsímil de Valencia, Librerías París-Valencia, 1979). Es sabido que dichas Cobles son apócrifas, y que actualmente se piensa que fueron escritas entre 1650 y 1680 , atribuyéndose su autoría al erudito valenciano Onofre Esquerdo, quien habría intentado con su obra prestigiar a los linajes valencianos de su tiempo, haciéndolos descendientes de los caballeros de la época de Jaime I: debiendo notarse que en la época en que se suponen escritas ya se hallaba suficientemente consolidada la fortuna de los Soler de Cornellá en el ámbito valenciano. Sobre las $\mathrm{Co}$ bles, vid. Miquel Coll i Alentorn, en la Gran Enciclopèdia Catalana, tomo VII, artículo "Febrer, Ja222222os en d(ic)ha parrochial una festividad a Nuestra Señora de los Dolores en su propio día. con la solemnidad de sermón, música y siriada correspondiente, cuya festividad deverá hazerse por todos los posehedores del vínculo, sin que se dexe de celebrar por ningún acontecimiento, y en el casso de no cumplirlo assí, es nuestra voluntad quede privado el posehedor, por aquel año, de todo lo que produxiesse en él, o huviere producido, y que satisfecha la fiesta de. Nuestra Señora de los Dolores, se celebre lo demás de misas por nuestras almas, a disposición de d(ic) ho reverendo clero, y lo mismo se entienda prevenido para en el caso de haver recaido el vínculo en $/ 93 \mathrm{v}$ dicho reverendo clero.

Señalemos que en su testamento, D. Francisco Soler escoge por intercesora esta advocación de la Virgen. Sobre las pinturas referidas, vid. AME. Protocolos de Francisco Gil de Agulló 1796, fols.376, 379v. Sobre el carácter nobiliario del culto a la Virgen de los Dolores, vid. Joaquín Serrano Jaén: "Un noble il.licità del segle XVII: Gaspar Soler y Chacon (1592-1629)", p. 42.

(107)- Vid. Ramón Baldaquí Escandell: "La reforma de la predicación en el XVIII valenciano...", pág. 124 y nota 129.

(108)- Vid. Jean Sarrailh: La España ilustrada de la segunda mitad del siglo XVIII, pp. 113114: recomendaciones de un arquitecto sobre disposición de las residencias particulares, publicadas en los Extractos de las juntas generales celebradas por la Real Sociedad Bascongada de los Amigos del País, y los criterios de Jovellanos al proceder a la renovación de su casa natal, instalando su gabinete en un cuarto con vistas y disponiendo una habitación con chimenea para el invierno, cuidadosamente decorada. En las pp. 125-126, Sarrailh recoge los elogios de Jovellanos a la disposición de algunas de las casas que visita. Fernand Braudel, Civilización material, economía y capitalismo (Madrid, Alianza editorial, 1984), tomo I, pp. 261-263, recoge los cambios que produce en el mobiliario de las viviendas el nuevo concepto de lo doméstico que introduce el siglo XVIII, que presta mayor atención al confort y a la intimidad, en detrimento de la solemnidad que el mobiliario de las casas pudientes había primado hasta entonces.

(109)- Fray Agustín de Arques Jover: Colección de pintores, escultores desconocidos, sacada de instrumentos antiguos, authénticos, edición de Inmaculada Vidal Bernabé y Lorenzo Hernández Guardiola (Alcoy, Caja de Ahorros de Alicante y Murcia, 1982), p. 97 (s.v. Borrás, P. Fr. 
Nicolás): "En la villa de Elche, en casa del mayorazgo de Soler de Cornellá, hay una pintura sobre tabla, primorosa, de Nuestra Señora de la Leche, de poco menos de vara".

(110)- AME. Protocolos de Francisco Gil de Agulló 1796, fol. 380 recto:

"Itt(em): un quadro de N(uestr) a S(eñor) a de la Leche, marco corlado: noventa r(eale)s"

Respecto de la tasación de las pinturas que aparecen abundantemente a lo largo de este inventario, cabe indicar que sus precios suelen estar al nivel del que alcanzan los muebles, y al parecer en relación directa con su tamaño, y así encontramos en la misma página del inventario en donde aparece la pintura de Borrás, "una cómoda de albaricoquero con quatro cajones y herrage dorado al fuego", tasada en 110 reales, dos mesillas de nogal taraceadas en maderas de diversos colores, a 100 reales cada una, y dos lienzos de la Virgen y el Niño, ovalados y con marcos de talla dorados, tasados en 50 reales cada uno. Señalaremos ahora la presencia de "una mesita madera de albericoquero (sic) con su tablero de juego de damas", tasada en veinte reales. Digamos por último que el cuadro de la Virgen de la Leche es, de todos los inventariados, el que alcanza mayor precio.

(111)- AME. Protocolos de Francisco Gil de Agulló 1796, fols. 379v-380v. En el folio $379 v$ aparece también la siguiente partida:

"Itt(em): un marquito de talla corlado con su quadro de S(a)n Geró(ni)mo pintado sobre vidrio: tres r(eale)s".

(112)- AME. Protocolos de Francisco Gil de Agulló 1796, fol. 380v. Al folio 379 aparece también "un espegito con marco de talla de distintos colores", tasado en seis reales.

(113)- AME. Protocolos de Francisco Gil de Agulló 1796, fols. 377, 378v, 380.

(114)- El gabinete parece que podría detectarse por la presencia de "un estante de librería de pino dado de color azul", y tres mesas de pino dotadas de escritorios que debían de ser portátiles (puesto que se indican como objetos separados que están "encima" de las mesas, y en un caso se indica que el escritorio es de nogal, y en otro que va taraceado en marfil), así como "una papelera, madera de cedro, con su segundo cuerpo de lo mismo": todo lo cual aparece inventariado sucesivamente (AME. Protocolos de Francisco Gil de Agulló 1796, fols. 377v-378). A pesar de la presencia del estante, no aparecen libros en el inventario, aunque debía de haberlos, puesto que el cabeza de familia era abogado y sus hermanos, uno eclesiástico y escritor y el otro oficial de marina. A lo largo del inventario aparecen, además, otras tres "papeleras", éstas de nogal, y una "papelerita" de pino, género de mueble dotado de cajones, cuyo uso aparece suficientemente descrito por su nombre.

En cuanto al salón, creemos que deben de pertenecerle los muebles y objetos relacionados desde la mitad del folio 380 a la mitad del $380 \mathrm{v}$, básicamente las "veinte y quatro sillas de nogal con golpes de talla y asientos de clin aforrados de damasco", tasadas a 30 reales cada una, que formarían conjunto con los "dos canapés de nogal con acientos (sic) de clin aforrados de damasco carmesí mostreado", a 180 reales la pieza, las "dos mecitas (sic) de nogal y embutido de otras maderas de diferentes colores" y las "dos medias mesas de nogal de quatro piez (sic) con golpes de talla, con su cajoncito delantero". Quizá estuviera también en esta pieza la "silla poltrona de nogal aforrada de indiana", que aparece tasada en 40 reales al final del inventario de la ropa, y es de suponer que habría más muebles, como alguna de las "dos mesas de pino con golpes de talla, con sus tableros imitados a piedra y los piez (sic) de color de canela", o de las "quatro rinconeritas de pino dadas de color de chocolate, de tres piez (sic)_cada una, con tableros imitados a piedra", y alguna de las tres "papeleras de nogal" de cuatro cajones y con herrajes dorados. Y se destinarían a sus puertas los "veinte y quatro marquitos con sus cristales, dados de corla", tasados a cuatro reales la pieza (AME. Protocolos de Francisco Gil de Agulló 1796 , fols. $380-380 \mathrm{v}, 382 \mathrm{v}$ ). 
(115)- AME. Protocolos de Francisco Gil de Agulló 1796, folio 380.

(116) A la cocina se indican pertenecer seis sillas de pino con asiento de anea, dos mesas de pino, un estante para colocar platos, cuatro sillas de pino con asientos de lo mismo y otras tres con asiento de soga, además de otra "mesa de pino para la arteza" (AME. Protocolos de Francisco Gil de Agulló 1796, fols. 378-379, recoge el mobiliario y objetos de la cocina).

(117)- AME. Protocolos de Francisco Gil de Agulló 1796, fols. 376, 378, 379 a 380v. Los "camones" fueron tasados en 100 reales (fol. $379 \mathrm{v}$ ); la mención de las colgaduras de cama, fols. 378-378v. Inventariados entre la ropa, aparecen cinco colchones de catre, cuatro de media cama, tres de cama entera, siete colchones de familia (fols. $381,382 \mathrm{v}$ ). En su testamento, don Francisco Soler lega cinco libras a cada uno de sus criados (fol. 38).

(1 18)- AME. Protocolos de Francisco Gil de Agulló 1796, fols. 376v a 379v. Una de las arcas era un mueble de lujo, elaborado en nogal y con figuras de talla en las esquinas (fol. $376 \mathrm{v}$ ); los guardarropas eran uno "grande", de albaricoquero, tasado en 200 reales, y otro de pino teñido y pintado (fols. 376v, 379). Aparece también una cómoda, mueble que en esta época se está difundiendo y que no se generalizará hasta el siglo XIX (fol. 380; vid. Fernand Braudel, op. cit., p. 259).

(119)- AME. Protocolos de Francisco Gil de Agulló 1796, fols. 376 y 379v. La madera de pino era la más utilizada para los enseres de casa y mobiliario de las gentes más humildes del Elche de la época, como puede verse a través de los inventarios post-mortem y las cartas dotales. Vid. Pedro Félix Jover Ibarra: Tipología notarial del archivo municipal de Elche en el siglo $X V I I I$, passim. La utilización de madera de nogal para muebles de lujo es una moda que se origina en los Países Bajos en el siglo XVI; la costumbre de pintar los muebles es de origen medieval y se perpetua en el mueble popular (Braudel, op. cit., pp. 238, 256-257).

(120)-AME. Protocolos de Francisco Gil de Agullo 1796, fol. 377 (la mesita de pino, que fue tasada en tres reales), $380 \mathrm{v}$ (el plato de peltre, en ocho reales).

(121)- AME. Protocolos de Francisco Gil de Agulló 1796, folio 377v, aparece "una paleta, tenasas y fuelles de la cosina fransesa: veinte r(eale)s": dos partidas similares, señaladas tan sólo "de cosina", aparecen a los folios 377 y 379 , tasadas en cinco y nueve reales, respectivamente, a pesar de que de la segunda se especifica que son "nuevas". Braseros encontramos cuatro, todos de cobre con su badil, y en dos de ellos se menciona también la tarima (fols. 377 a $378 v$ ). En el inventario se menciona también el "esterado" y "pelfudos" (sic) de la casa que don Francisco Soler de Cornellá poseía en Alicante, tasado en 200 reales (fol. 378v), aunque es de destacar que no aparecen alfombras, tapices, reposteros, tapetes ni guadamecíes de ningún género, que sin embargo encontramos abundantemente en el inventario de los bienes del marino $\mathrm{D}$. Jorge Juan y Santacília, pariente de los Soler (vid. Rafael Navarro Mallebrera y Ana María Navarro Escolano: Inventario de bienes de Jorge Juan y Santacilia. Transcripción y estudio de la biblioteca (Alicante, Instituto de Estudios Juan Gil-Albert, 1987). También se mencionan dos calentadores de cama (fol. 377-377v). En el mismo capítulo del confort doméstico podrían alinearse las vidrieras de ventanas y balcones, que aparecen con abundancia a lo largo de todo el inventario, y de las que la partida de las pertenecientes a la casa de Alicante importa 340 reales, y las cortinas, de las que se citan 27 unidades, pero sólo de cinco se especifica que son "para balcones" (fols. $380 \mathrm{v}-382 \mathrm{v}$ ). Cabe alinear también con todo lo antecedente la iluminación, asegurada por cinco velones de cobre y dos candelabros de lo mismo, más otros cuatro de platá, un farol de cristal y "dose antorchas de madera para los balcones" (fols. 377, 378v, 379v y 383).

(122)- AME. Protocolos de Francisco Gil de Agullo 1796, fols. 381 y $382 \mathrm{v}$.

(123)- AME. Protocolos de Francisco Gil de Agulló 1796, folios 377 (loza de Alcora) y $380 \mathrm{v}$ (las medias vajillas inglesas): las últimas se tasan en 200 y 100 reales la blanca y la decora- 
da, respectivamente, mientras que la alcoreña alcanza tan sólo 20 reales. La cómoda es un mueble que, según Braudel en su obra tantas veces citada, no se difunde hasta el siglo XIX (vid. $\mathrm{Ci}$ vilización material, economía y capitalismo..., p. 259).

\section{(124)- AME. Protocolos de Francisco Gil de Agulló 1796,:}

"una perola de cobre para haser dulce, grande: once r(eale)s" (fol. 378v)

"otra de lo mismo, más pequeña: seis r(eale)s" (fol. 378v)

"una garrafa de cobre para agua de nieve: siete r(eale)s" (378v)

"una chocolatera grande con su monelillo de madera: seis r(eale)s" (fol. 379)

"una cagita de nogal con serraja y llave y asita de fierro, que sirve para colocar en ella botes de tabaco: diez r(eale)s" (fol. 380)

"un molinito de madera para moler café: trese reale)s" (fol. 380v).

El café es una bebida que se está popularizando en la época: en Francia era aún raro en provincias hacia 1787. Sin embargo, en 1773, Jorge Juan, hombre cortesano, disponía de dos molinillos para café, si bien cabe suponer que no lo consumiría con la asiduidad que el chocolate o el té (había residido en Inglaterra), substancias de las que poseía abundantes provisiones. Vid. Navarro Mallebrera-Navarro Escolano, op. cit., pp. 32-33; Fernand Braudel: Civilización material..., p. 217.

Se citan además en el inventario:

"ocho bandegitas de cherol para asientos de botellas: dose r(eale)s" (fol. 380v)

"dos tonelitos para vino, el uno con seis sercos (sic) de fierro y grifo, en 14 r(eale)s corr(iente)s, y el otro con dos cercos de fierro, en ocho r(eale)s" (fol. 380v)

"cinco marrajas de vidrio para vino, vestidas de pleyta: catorze r(eale)s" (fol. 377).

(125)- Además de la garrafa y perolas de cobre ya citadas, encontramos "un posal de cobre sin cadena para sacar agua: cinco r(eale)s", una cuchara y una espumadera de cobre con mango de hierro, unas "orteras" con mango de cobre, un almirez, una "grajonera" y "un posal de cobre con cadena de fierro: seis r(eale)s" (AME. Protocolos de Francisco Gil de Agulló 1796, fols. $378 \mathrm{v}-379 \mathrm{v})$. También aparecen relacionados unos ganchos para el pozo, puesto que en Elche el aprovisionamiento de aguas dulces se hacía mediante aljibes que recogían las de lluvia, y no hubo fuentes públicas de agua potable hasta 1789, año en que se concluyó la conducción de aguas financiada por el obispo D. José Tormo (Vid. Alejandro Ramos Folqués: Historia de Elche, pp. 319-321).

(126)- AME. Protocolos de Francisco Gil de Agulló 1796, fols. 382v-383. Sin embargo, en su testamento D. Francisco Soler dispuso que se entregase una "alaxa de plata" a cada uno de sus hijos y hermanos, especificando que dejaba "el espadin" a su hijo D. Leonardo, y a su esposa "la bandeja de plata grande con las armas de realce", por lo que las piezas así distribuidas, como el resto de los bienes de que el finado dispuso en su testamento y los pertenecientes a sus vínculos, no aparecen en los inventarios que manejamos: vid. en el protocolo citado, fols. $37 \mathrm{v}$ 38.

(127)- AME. Protocolos de Francisco Gil de Agulló 1796, fols. 384-384v. Aparecen también dos galeras, tasadas en 400 y 200 reales, y dos carros, que serían sin duda para los usos agrícolas.

(128)- AME. Protocolos de Francisco Gil de Agulló 1796, fols. 383v-384v, los muebles existentes en la heredad del Palombar, en la que destacan los únicos cuadros de tema profano (salvo los retratos) que aparecen en el inventario: "siete quadros de las siete maravillas, con marcos dados de negro: veinte y cinco r(eale)s" (fol. 384v). Sobre las instalaciones de que esta- 
ba dotada esta finca, vid. el texto transcrito más arriba, en la nota 38 (AME. Protocolos de Francisco Gil de Agulló 1796, folios 54v-55).

Debemos indicar aquí que no creemos que el inventario que hemos utilizado refleje la totalidad de los bienes muebles de D. Francisco Soler de Cornellá. En primer lugar, no aparece mobiliario alguno de la casa que poseía en la ciudad de Alicante, en la que, en 1800, residía su viuda doña María Rafaela Juan, ni tampoco de la que existía en su hacienda de la partida de Benicaixer, que sabemos estaba dotada de una bodega equipada. Tampoco encontramos ninguna pieza de ropa de uso personal, ni vemos objetos de joyería, ni aún las clásicas hebillas, que tan frecuentes son en los inventarios coetáneos, incluso de gente mucho más modesta. Aparece muy poca vajilla y pocos cubiertos, siendo muy llamativa la falta de objetos de cristal. Y finalmente, indiquemos que no aparecen libros (como ya hicimos notar), aunque indudablemente debía de haberlos, siquiera sea por la presencia de un estante de librería destinado a contenerlos.

(129)- De la nobleza ilicitana de la época conocemos el testamento del noble D. Bernardo Juan y Santacília, de 1797, citado por Pedro Ruiz Torres (Señores y propietarios..., p. 332-333), en el que, por desgracia, no se citan sino propiedades inmuebles; actualmente dicho testamento no se halla con la signatura referenciada en el lugar citado. Conocemos también la división y partición de los bienes de D. Joaquín Perpiñán y Pasqual, datada el 11 de marzo de 1798, pero en éste no figuran la ropa blanca, colchones, colchas, menaje de la casa, muebles, plata y coches, que se repartieron proporcionalmente y por suertes entre sus herederos (vid. Pedro Félix Jover Ibarra: Tipología notarial..., páginas 504-506, número 1.271).

Hemos consultado el inventario de los bienes del famoso matemático y marino $D$. Jorge Juan y Santacília (muerto en 1773), tío de doña María Rafaela Juan y Ximénez de Urrea, y a quien sucedió como heredero su hermano D. Bernardo Juan, inventario que ha sido transcrito y estudiado por D. Rafael Navarro Mallebrera y D. Ana María Navarro Escolano (Inventario de bienes de Jorge Juan y Santacília..., 189 páginas, passim). También hemos utilizado el artículo de doña María Cruz Cabeza Sánchez-Albornoz y doña María Milagros Cárcel Ortí: "La biblioteca y otros bienes de D. Francisco Fernández Campomanes (1760-1838)", en Saitabi, XXXVI, (Valencia, 1986), pp. 71-99, publicación que, por centrar su atención en la biblioteca, reseña el resto de los bienes en forma sumaria, aunque utilizable.

(130)- AME. Protocolos de Francisco Gil de Agulló 1796, fol. 55.

(131) - AME. Protocolos de Diego Mira 1740, fol. 90.

(132)- AME. Protocolos de Francisco Gil de Agulló 1796, fols. 36-37.

(133)- De éstos, 88.866 reales y 7 dineros constituían el importe de sus legítimas y otros bienes habidos tras su matrimonio. Vid. AME. Protocolos de Francisco Gil de Agulló 1796, fols. 55 y 388-389v. En su testamento, D. Francisco Soler hace relación de los bienes que su esposa recibió tras el matrimonio, disponiendo que se le abonen (loc. cit., fols. 37-37v).

(134)- AME. Protocolos de Francisco Gil de Agulló 1796, fol. 37v. La venta se hizo el dos de septiembre de 1793, precio de 1.100 libras: vid. Pedro Félix Jover Ibarra: Tipología notarial $\ldots$, fols. 331-332, número 687 ( 1 libra $=1$ peso= 10 reales). Posteriormente, este agua no redimida, tras la muerte de D. Joaquín Perpiñán, pasó a su hija Ursula, ya entonces viuda de D. Antonio Tárrega (AME. Rústica 1808, vol. I, fols. 158-158v). Sobre D. Joaquín Perpiñán y Pasqual, vid. Pedro Ruiz Torres: Señores y propietarios..., pp. 349-350: precisar que D. Joaquín Perpiñán murió en 1798, dejando un hijo de igual nombre. Sobre la fecha de la boda de D. Leonardo Soler, vid. Barón de Finestrat: Nobiliario..., p. 315.

(135)- AME. Protocolos de Diego Mira 1740, fols. 89-89v:

"Primeram(en)te: encomendamos nuestra ánimas a Dios nuestro Señor, que las crió y redi- 
redimió con su preciosísima sangre, los cuerpos a la tierra, de cuyo elemento fueron formados, los quales queremos sean enterrados en la iglesia parroquial de S(an)ta María de esta villa, donde somos feligreses, en nuestro entierro proprio ( $\mathrm{sic}$ ) de los Soleres, revestidos//89v con el hábito de nuestro padre San Fran(cis)co, y nuestro entierro se execute general, de cuerpo presente, con asistencia de las tres parroquias, los religiosos del convento de Nuestra Señora de la Merced y los de de S(an)ta Clara, y los residentes de d(ic)has parroquias.

"Otrosí, mandamos que por nuestras ánimas e intención se celebren dos mil misas resadas, por metad (sic), repartidas en esta forma: seiscientas sessenta y seis en d(ic)ha parroquial de S(an)ta María; en la del Salvador, quatrocientas; en la capilla de S(a)n Juan de Letrán, convento de Nuestra Señora de la Merced de esta villa, quatrocientas; en el convento de Nuestro Padre San Joseph, quatrocientas; y las ciento treinta y quatro restantes, en la parroquial del señor San Juan Bautista; pagando por cada una de ellas la limosna acostumbrada".

(folio 90): "Otrosí: mandamos y legamos a los Santos Lugares de Jerusalém, dies sueldos de moneda p(o)r una vez; y para ayuda a redimir los pobres cautivos christianos, otros dies sueldos, por una vez".

(136)- AME. Protocolos de Francisco Gil de Agullo 1796, folios 34v-35:

"Prim(erament)e: encomiendo mi alma a Dios Nuestro Señor, que la crió de la nada y la redimió con la presiosísima sangre de Nuestro Señor Jesu-Christo, su unigénito Hijo, y el cuerpo mando a la tierra, de cuyo elemento fue formado. Y quiero que, llegado mi fallecimiento y cumplidas las veinte y quatro horas, sea enterrado en la ynsigne iglesia parroquial de Santa María de esta villa, en del entierro antiguo de los Soleres de Cornellá propio, donde yazen mis padres, hijos, hermanos y demás ascendientes, el mismo que existe junto a la pila y pilar//35 del crusero de la parte de medio día, y que sea revestido con ábito, capilla, cuerda y alpargates (sic) de Nuestro Seráfico Padre y mi patrón, San Fran(cis)co de Asís, y que en la ponpa (sic) de entierro y funeral procuren mis infrafirmados albaceas evitar toda superfluidad, siñéndose al menos gasto que admita la buena razón.

"Itt(em): señalo quatrocientos pesos o libras corrientes para todo el funeral y bien de mi alma, el qual se ha de distribuhir por mis albaceas de esta suerte: que de este caudal se paguen todos los gastos de entierro, cera, ábito y demás del funeral, y lo que restare se celebre de misas rezadas por mi alma, la de mi muger y los míos, con la limosna de quatro reales vellón cada una, en los altares e iglesias y por los sacerdotes que a mis albaceas les pareciere serán más brevemente celebradas, exceptando empero aquella porción o número que le correspondan a la iglesia de que yo fuere feligrés al tiempo de mi muerte, las que quiero se celebren en ella con la propia limosna.

"Itt(em): mando y lego de limosna por una ves al santo hospital de esta villa, dies libras; a los Santos Lugares de Palestina, dos libras; y a la redemción (sic) de cautivos, otras dos libras".

(137)- Vid. Barón de Finestrat: Nobiliario..., pp. 158-159. Pedro Ruiz Torres: Señores y propietarios..., p. 332. Además de estos legados, dejaba don Bernardo Juan 500 libras a sus criados y 200 a tres sobrinas, además de cuatro haciendas y un substancioso vínculo, el cual terminó en manos de D. Juan Roca de Togores. Es muy posible que en la generosidad y magnificencia testamentarias de don Bernardo tuviese parte, junto a la solidez de su fortuna, muy superior a la de don Francisco Soler de Cornellá, el hecho de no contar con descendientes directos, por lo que le heredaron su segunda esposa, doña María Josefa Vaílo de Llanos, y varios sobrinos.

(138)- Vid. Alejandro Ramos Folqués, op. cit., pp. 677-678. 


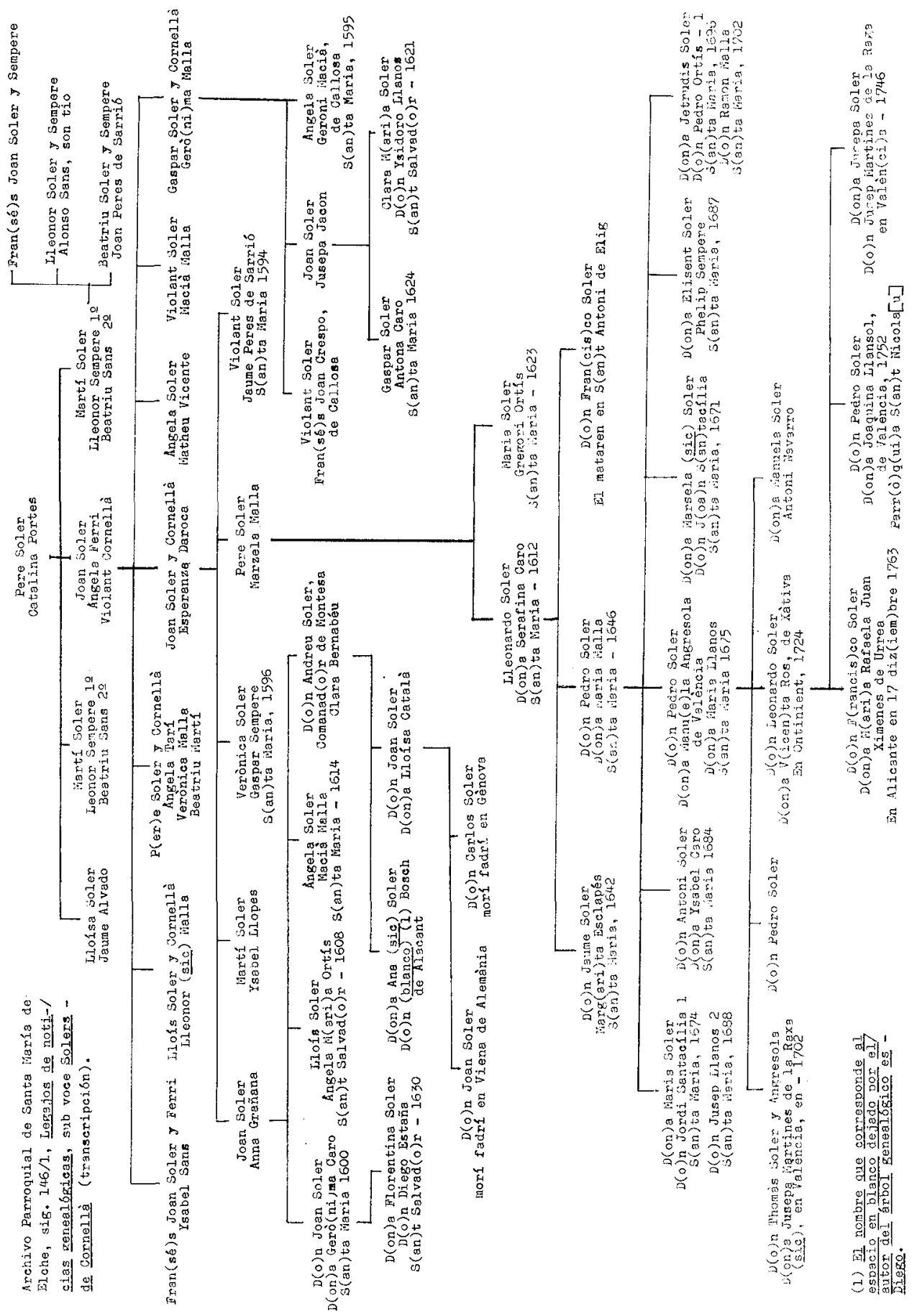

